\title{
Molecular weight-dependent degradation and drug release of surface-eroding poly(ethylene carbonate)
}

Bohr, Adam; Wang, Yingya; Harmankaya, Necati; Water, Jorrit Jeroen; Baldursdottir, Stefania G.; Almdal, Kristoffer; Beck-Broichsitter, Moritz

\author{
Published in: \\ European Journal of Pharmaceutics and Biopharmaceutics
}

Link to article, DOI:

10.1016/j.ejpb.2017.02.011

Publication date:

2017

Document Version

Peer reviewed version

Link back to DTU Orbit

Citation (APA):

Bohr, A., Wang, Y., Harmankaya, N., Water, J. J., Baldursdottir, S. G., Almdal, K., \& Beck-Broichsitter, M. (2017). Molecular weight-dependent degradation and drug release of surface-eroding poly(ethylene carbonate). European Journal of Pharmaceutics and Biopharmaceutics, 115, 140-148. https://doi.org/10.1016/j.ejpb.2017.02.011

\section{General rights}

Copyright and moral rights for the publications made accessible in the public portal are retained by the authors and/or other copyright owners and it is a condition of accessing publications that users recognise and abide by the legal requirements associated with these rights.

- Users may download and print one copy of any publication from the public portal for the purpose of private study or research.

- You may not further distribute the material or use it for any profit-making activity or commercial gain

- You may freely distribute the URL identifying the publication in the public portal 


\title{
Molecular weight-dependent degradation and drug release of surface- eroding poly(ethylene carbonate)
}

\author{
Adam Bohr ${ }^{1}$, Yingya Wang ${ }^{1}$, Necati Harmankaya ${ }^{1}$, Jorrit J. Water ${ }^{1}$, Stefania Baldursdottír ${ }^{1}$, \\ Kristoffer Almdal ${ }^{2}$ and Moritz Beck-Broichsitter $3,4, *$ \\ ${ }^{1}$ Department of Pharmacy, University of Copenhagen, Copenhagen, Denmark \\ 2 Department of Micro- and Nanotechnology, Technical University of Denmark, Kongens Lyngby, Denmark \\ ${ }^{3}$ Department of Pharmaceutics and Biopharmacy, Philipps-Universität, Marburg, Germany \\ ${ }^{4}$ Present address: Chemical and Pharmaceutical Development, Bayer Pharma AG, Wuppertal, Germany
}

* Corresponding author: Moritz Beck-Broichsitter, PhD; Chemical and Pharmaceutical Development, Bayer Pharma AG, Friedrich-Ebert-Strasse 217-333, D-42117 Wuppertal, Germany

Tel.: 0049214 3000; Fax: 0049202363867

E-mail: $\underline{\text { moritz.beck-broichsitter@bayer.com }}$

Conflict of interest: The authors disclose that no conflicting interests associated with the manuscript exist.

Submission declaration: All authors have contributed to the conception and design of the study and acquisition, analysis and interpretation of data. All authors have drafted the article and revised it critically for important intellectual content. All authors have approved the final article. All authors agree to be accountable for all aspects of the work. The authors certify that this manuscript, or any part of it, has not been published and will not be submitted elsewhere for publication while being considered by Acta Biomaterialia.

Role of funding source: The "Danish Council for Independent Research" [grant no. 12-131927], Lundbeck Foundation [grant no. R218-2016-1323] and Innovation Fund Denmark [grant no. 041-2010-3] provided financial support for the conduct of the research. The funding sources had no involvement in the study design; in the collection, analysis and interpretation of data; in the writing of the report; or in the decision to submit the article for publication.

\begin{abstract}
Poly(ethylene carbonate) (PEC) is an unique biomaterial showing significant potential for controlled drug delivery applications. The current study investigated the impact of the molecular weight on the biological performance of drug-loaded PEC films.
\end{abstract}


Following the preparation and thorough physicochemical characterization of diverse PEC (molecular weights: 85, 110, 133, 174 and $196 \mathrm{kDa}$ ), the degradation and drug release behavior of rifampicin- and bovine serum albumin-loaded PEC films was investigated in vitro (in the presence and absence of cholesterol esterase), in cell culture (RAW264.7 macrophages) and in vivo (subcutaneous implantation in rats). All investigated samples degraded by means of surface erosion (mass loss, constant molecular weight), which was accompanied by a predictable, eroding-controlled drug release pattern. Accordingly, the obtained in vitro degradation half-lives correlated well with the observed in vitro half-times of drug delivery $\left(R^{2}=0.96\right)$. Here, the PEC of the highest molecular weight resulted in the fastest degradation/drug release. When incubated with macrophages or implanted in animals, the degradation rate of PEC films superimposed the results of in vitro incubations with cholesterol esterase. Interestingly, SEM analysis indicated a distinct surface erosion process for enzyme-, macrophage- and in vivo-treated polymer films in a molecular weight-dependent manner.

Overall, the molecular weight of surface-eroding PEC was identified as an essential parameter to control the spatial and temporal on-demand degradation and drug release from the employed delivery system.

\section{KEYWORDS}

Controlled drug delivery; molecular weight; poly(ethylene carbonate); protein release; rifampicin; surface erosion
ABBREVIATIONS
BSA bovine serum albumin
$Ð \quad$ dispersity
DSC differential scanning calorimetry
$[\eta] \quad$ intrinsic viscosity
$\eta_{\mathrm{sp}} \quad$ specific viscosity
FITC fluoresceine isothiocyanate
GPC gel permeation chromatography 


$\begin{array}{ll}M_{\mathrm{w}} & \text { weight-average molecular weight } \\ \text { PBS } & \text { phosphate-buffered saline } \\ \text { PEC } & \text { poly(ethylene carbonate) } \\ \text { SD } & \text { standard deviation } \\ \text { SEM } & \text { scanning electron microscopy } \\ \mathrm{t}_{1 / 2} & \text { half-time/half-life } \\ T_{\mathrm{g}} & \text { glass transition temperature } \\ \text { wt. } \% & \text { weight percent } \\ \text { XRPD } & \text { X-ray powder diffraction }\end{array}$

\section{INTRODUCTION}

Advances in the field of chemical engineering and the biomedical sciences have made polymer drug carriers available, which allow for modification of the delivery rate of the embedded therapeutic agent [1]. The drug release may occur constantly over an extended period of time, typically by means of polymer degradation and/or diffusion through the polymer matrix, with the aim of obtaining constant plasma levels, reducing side effects and prolonging dosing intervals [2]. Biodegradable polyesters such as poly(lactide-co-glycolide) have been most-frequently utilized as matrix materials for controlled drug delivery devices [3, 4]. However, the hydrolytic degradation behavior (i.e., bulk erosion [5], formation of acidic microclimate within the drug carrier [6]) often results in a rather uncontrolled drug release profile [7] and chemical instability for numerous therapeutic agents [8,9].

In contrast, polymers that degrade solely by surface erosion have demonstrated more predictable drug release kinetics [10]. Biodegradable poly(ethylene carbonate) (PEC) is a promising example of such polymer [11]. Diverse PEC-based drug delivery vehicles have been shown to degrade from the surface in vitro and in vivo [11-13], resulting in a favorable drug release profile $[14,15]$. Furthermore, the degradation of PEC is triggered by specific enzymes and cells $[16,17]$ making this type of polymer especially attractive for on-demand drug release to desired sites within the body [18]. Despite the significant potential of PEC for controlled drug delivery applications, only scant information is available describing the biomedical performance (i.e., biodegradation and drug release) of drug delivery vehicles composed of PEC of different molecular weight [19]. 
In this respect, the current study aimed to close this gap by investigating the impact of the polymer molecular weight on the degradation of and drug release rate from surface-eroding PEC films in detail. Polymers and polymer films either loaded with rifampicin or fluorescentlylabelled bovine serum albumin (BSA) were thoroughly characterized before studying their in vitro degradation and drug release behavior in the absence and presence of the enzyme cholesterol esterase. Degradation tests in cell culture (i.e., RAW264.7 macrophages) and in vivo (i.e., subcutaneous implantation in rats) underlined the unique potential of PEC for prolonged drug delivery applications.

\section{MATERIALS AND METHODS}

2.1 Materials. PEC, QPAC ${ }^{\circledR} 25$ was purchased from Empower Materials (USA). PEC polymers of lower molecular weight were obtained by thermal hydrolysis in boiling water (Figure S1, Supplementary materials) [16, 17, 19]. rifampicin ( $\geq 97 \%)$, fluorescein isothiocyanate (FITC)-labeled BSA ( $\geq 7 \mathrm{~mol} \mathrm{FITC/mol} \mathrm{BSA}$ ) and cholesterol esterase (from porcine pancreas) were acquired from Sigma-Aldrich (UK). All other chemicals and solvents were of analytical grade and used without further purification.

2.2 Gel permeation chromatography (GPC). Samples were dissolved in chloroform (3-4 mg/ml). After filtration (0.2 $\mu \mathrm{m}$; Acrodisc ${ }^{\circledR}$, Pall, Germany), $100 \mu \mathrm{l}$ of the sample solution was injected into the system, consisting of two columns from Polymer Laboratories (PL-gel MIXED-D; $300 \times 7.5 \mathrm{~mm}$; bead diameter $5 \mu \mathrm{m}$ ) and a differential refractive index detector (SpectraSystem RI-150, Thermo Electron Corp., USA). The elution was performed with chloroform at a flow rate of $1 \mathrm{ml} / \mathrm{min}$ and toluene as flow-rate marker. Poly(methyl methacrylate) standards of known molar masses were used for calibration.

2.3 Viscosity measurements. The viscosity of PEC samples dissolved in chloroform was measured using a capillary viscometer of the Ubbelohde Semi-Micro dilution type (No. $50, \mathrm{~N} 213, \mathrm{CANNON}$ Instrument Company, USA) at $25.0 \pm 0.2^{\circ} \mathrm{C}$. Values for the specific $\left(\eta_{\mathrm{sp}}\right)$ and intrinsic viscosity $([\eta])$ were calculated using standard equations.

2.4 Differential scanning calorimetry (DSC). The glass transition temperature $\left(T_{\mathrm{g}}\right)$ of 
polymers and polymer films was determined using a differential scanning calorimeter (Discovery DSC, TA Instruments, Denmark). Samples ( 3-5 mg) were scanned at a rate of 10 ${ }^{\circ} \mathrm{C} / \mathrm{min}$ from $-40{ }^{\circ} \mathrm{C}$ to $190{ }^{\circ} \mathrm{C}$ under a nitrogen atmosphere.

2.5 X-ray powder diffraction (XRPD). Wide-angle XRPD patterns were recorded on a X'Pert PROMPD X-ray diffractometer (PANalytical, The Netherlands). Samples were measured in Bragg Brentano reflection mode in the $2 \theta$ range of $5-37^{\circ}$ using a PIXel detector (step size of $\left.0.039^{\circ}\right)$. The $\mathrm{X}$-ray source was Ni-filtered $\mathrm{CuK}_{\alpha 1}$ radiation $(\lambda=1.541 \AA)$. The operating current and voltage were $40 \mathrm{~mA}$ and $45 \mathrm{kV}$, respectively. The aluminum sample holder was spun throughout data collection to avoid orientation artifacts.

2.6 Scanning electron microscopy (SEM). Samples were placed on double-sided carbon tape, mounted on stubs and sputter coated with a $5 \mathrm{~nm}$ layer of gold using a Leica EM ACE200 (Germany) prior to sample imaging. The images were acquired with an FEI/Philips XL30 FEG (USA) at an acceleration voltage of $2 \mathrm{kV}$ using the secondary electron detector.

2.7 Preparation of polymer films. PEC films were fabricated by a solvent casting technique $[20,21]$. Therefore, PEC without or with added rifampicin (10 wt.\% per polymer mass) were accurately weighed and then dissolved in chloroform at a concentration of 100 $\mathrm{mg} / \mathrm{ml}$. For films loaded with BSA, PEC was first dissolved in chloroform $(100 \mathrm{mg} / \mathrm{ml})$ containing Span ${ }^{\circledR} 80(1 \mathrm{mg} / \mathrm{ml})$. BSA was dissolved in water $(10 \mathrm{mg} / \mathrm{ml})$ in parallel before mixing the two solutions (ratio of 9/1 (v/v)) using a homogenizer (T25 Ultra-Turrax ${ }^{\circledR}$, IKA, Germany). Film solutions $(500 \mu \mathrm{l})$ were then transferred to custom-made Teflon ${ }^{\circledR}$ dishes (diameter: $10 \mathrm{~mm}$, height: $3 \mathrm{~mm}$ ) and the organic solvent was allowed to evaporate under a fume hood overnight. The films were then cut into discs, and dried under reduced pressure $(\sim 0.1 \mathrm{mbar})$.

2.8 Enzymatic polymer degradation. Polymer film samples ( $25 \mathrm{mg})$ were transferred to $2 \mathrm{ml}$ of phosphate-buffered saline (PBS, pH 7.4) without or with added cholesterol esterase $(0.1 \mathrm{mg} / \mathrm{ml})$. The films were incubated at $37^{\circ} \mathrm{C}$ with shaking (Rotatherm ${ }^{\circledR}$, Gebr. Liebisch, Germany). The medium was exchanged every 3-4 d. At predetermined time points the incubation was terminated by removal of the supernatant. Polymer films were washed several times with distilled water and subsequently freeze-dried (Beta I, Christ, 
Germany) overnight. The remaining film mass and molecular weight was determined gravimetrically (BP 211 D, Sartorius, Germany) and by GPC as described above, respectively.

2.9 Drug release from polymer films. The in vitro drug release studies were carried out in PBS without or with added cholesterol esterase $(0.1 \mathrm{mg} / \mathrm{ml})$ under sink conditions. $\sim 30 \mathrm{mg}$ of rifampicin-loaded (drug loading of $10 \mathrm{wt} . \%$ ) or BSA-loaded (drug loading of 1 wt.\%) PEC films were incubated in the release medium while shaking at $37^{\circ} \mathrm{C}$. The release medium was removed at each sampling time point and replaced with fresh medium before determining the cumulative drug release.

2.10 Rifampicin quantification. Rifampicin concentrations were assessed by reversed-phase high performance liquid chromatography on a Shimadzu system (Japan) using a Phenomenex Kinetex XB-C18 $(50 \mathrm{~mm} \times 2.1 \mathrm{~mm}, 2.6 \mu \mathrm{m})$ column (Denmark) (flow rate of $0.5 \mathrm{ml} / \mathrm{min}$ ). Samples were analyzed using a 5-15\% (v/v) B gradient over $3.5 \mathrm{~min}$ with the mobile phases composed of solvent A $\left(95 / 5 \mathrm{MeCN} / \mathrm{H}_{2} \mathrm{O}+0.1 \%\right.$ TFA (v/v)) and solvent B $\left(5 / 95 \mathrm{MeCN} / \mathrm{H}_{2} \mathrm{O}+0.1 \%\right.$ TFA (v/v)). Rifampicin was detected at a wavelength of $369 \mathrm{~nm}$.

2.11 BSA quantification. BSA concentrations were determined by fluorescence spectroscopy (FLUOstar OPTIMA, BMG labtech, Germany) and the bicinchoninic acid protein assay reagent (Pierce, USA). Fluorescence intensity $\left(\lambda_{\mathrm{ex}}=460 \mathrm{~nm}\right.$ and $\left.\lambda_{\mathrm{em}}=515 \mathrm{~nm}\right)$ was assayed in 96-well microplates. The cumulative amount of BSA released was then calculated as described above.

2.12 Cell culture. Murine macrophages (RAW264.7) were acquired from ATCC (TIP71, USA). Cells were maintained in Dulbecco's Modified Eagle's Medium supplemented with penicillin $(100 \mathrm{U} / \mathrm{ml})$, streptomycin $(100 \mu \mathrm{g} / \mathrm{ml}), 2 \mathrm{mM} \mathrm{L-glutamine} \mathrm{(all} \mathrm{from} \mathrm{Sigma-Aldrich,}$ UK) and $10 \%(\mathrm{v} / \mathrm{v})$ of fetal bovine serum (PAA Laboratories, Austria) and cultured in an air atmosphere conditioned with $5 \% \mathrm{CO}_{2}$ at $37^{\circ} \mathrm{C}$. The medium was changed three times per week and cells were split twice weekly (cell detachment by scraping). Cells were used between passages 5 and 12 .

2.13 Cellular polymer degradation. PEC films $(\sim 50 \mathrm{mg})$ were disinfected with ethanol before transferring them into prefilled (50,000 macrophages per ml medium, $2.5 \mathrm{ml}$ ) 6-well cell culture plates. The culture plates were then incubated as outlined above. At 
predetermined time points, the incubation was stopped by removing the films from the well plates. The films were treated with 1 wt.\% aqueous Triton X-100 detergent (Sigma-Aldrich, $\mathrm{UK}$ ) for $60 \mathrm{~min}$ and then extensively rinsed with distilled water. After freeze-drying, the remaining film mass and molecular weight was determined as outlined above.

2.14 Polymer degradation in vivo. Male Sprague-Dawley rats ( $250 \mathrm{~g}$; Charles River, Denmark) were used for the in vivo evaluation of polymer degradation. Animals were allowed free access to water and food and were housed under controlled environmental conditions (constant temperature and humidity with a $12 \mathrm{~h}$ dark-light cycle).

The animals were anaesthetized by isoflurane/oxygen inhalation (Scanvet, Denmark) and kept with the mask during the entire surgical procedure. Buprenorphine $(0.3 \mathrm{ml}, 10 \%$ in isotonic saline) was administered subcutaneously preoperatively. For each rat, the skin was incised along the midline of the back and two pockets were prepared by dissecting the subcutaneous tissue on both right and left side of the incision. Into each pocket, one polymer film of $1 \mathrm{~cm}^{2}$ (thickness of 1-2 mm) of predetermined molecular weight (around $60 \mathrm{mg}$ in total) was placed followed by skin closure. Following 3, 7 and $10 \mathrm{~d}$, animals were anaesthetized and the films were retrieved, cleaned and freeze-dried for weighing and molecular weight determination. Animals were finally euthanized by an overdose of sodium pentobarbital.

All experiments and procedures described herein were in accordance with the National Institutes of Health guidelines on the care and use of laboratory animals. The study protocol was further approved by the Danish Animal Experiments Inspectorate (approval no. 201415-0201-00031).

2.15 Statistics. All experiments/measurements were carried out in triplicate and values are presented as the mean \pm standard deviation (SD) unless otherwise stated. To identify statistically significant differences, an unpaired $t$-test analysis was performed. Probability values of $p<0.05$ were considered significant.

\section{RESULTS \& DISCUSSION}


The medical field would clearly profit from polymer excipients allowing for a predictable drug release behavior. Further, it would be attractive to design drug delivery vehicles with certain specificity for cells and/or tissues and thus, an on-demand release in order to minimize systemic drug distribution [18]. This task is often difficult to achieve, especially when employing bulk-eroding polymers such as poly(lactide-co-glycolide) $[5,7,22]$. In contrast, surface-eroding PEC comprises significant potential to meet these specific requirements. However, as the speed of biodegradation dictates the release kinetics of the encapsulated therapeutic agent for drug delivery devices undergoing surface erosion, a deeper understanding of the influence of the molecular weight of the utilized PEC is therefore, considered important.

\subsection{Characterization of polymers and drug-loaded polymer films. The} physicochemical properties of the synthesized PEC are outlined in Table 1. Polymers with different weight-average molecular weight $\left(M_{\mathrm{w}}\right)$ were prepared by thermal hydrolysis of commercially available PEC196 (Figure S1, Supplementary materials) $[16,17,19]$ with the aim to study the impact of $M_{\mathrm{w}}$ on the biomedical performance of polymer films in detail. The $M_{\mathrm{w}}$ of degraded polymer samples, assessed by means of GPC, ranged between 196 and $85 \mathrm{kDa}$. GPC analysis further indicated relatively broad dispersities $(\nexists)$ of degraded polymers $(>2.0)$ [12], which were, however, more narrowly distributed than the starting material (PEC196) (Figures S1B and S2, Supplementary materials). The approach of $Ð$ towards 2 is an indication of random chain scission during the employed degradation process. Proton nuclear magnetic resonance spectroscopy confirmed the composition ( $>95 \%$ ethylene glycol) of the utilized polymers (data not shown).

\section{[insert Table 1 here]}

The viscosity of the polymers dissolved in chloroform increased as a function of the polymer concentration and $M_{\mathrm{w}}$ (Figure S3, Supplementary Materials). [ $\left.\eta\right]$ values ranged between 0.6 and $1.0 \mathrm{dl} / \mathrm{g}$ (Table 1). The relationship of $[\eta]$ and $M_{\mathrm{w}}$ of PEC dissolved in chloroform is illustrated in Figure S4 (Supplementary Materials), which showed a linear correlation for the investigated polymers. Application of the Mark-Houwink equation for the specific polymer-solvent system, gave a value of $0.032 \mathrm{dl} / \mathrm{g}$ and 0.66 for $k$ and $\alpha$, respectively. The exponent $\alpha$ is indicative of the PEC chain geometry in chloroform. A value of 0.5 indicates 
a $\theta$-solvent, while a value between 0.5 and 0.8 reflects a random polymer coil in a "good" solvent.

DSC measurements of the distinct polymers showed minor differences in $T_{\mathrm{g}}$, with all polymers having a $T_{\mathrm{g}}$ below room temperature (Table 1). The $T_{\mathrm{g}}$ of PEC85 $\left(15^{\circ} \mathrm{C}\right)$ was the lowest, while that of PEC196 was the highest $\left(17^{\circ} \mathrm{C}\right)$. Elevated $T_{\mathrm{g}}$ values are typically seen when increasing the $M_{\mathrm{w}}$ of amorphous and semi-crystalline polymers (Flory-Fox relationship) [23]. It was further observed, that Rifampicin-loaded PEC films (10 wt.\%) showed a higher $T_{\mathrm{g}}$ compared to the polymers alone. Thus, rifampicin shifted the drug-polymer mixture toward higher $T_{\mathrm{g}}$, most-likely due to an anti-plasticizer effect of this drug [24, 25]. For all rifampicinloaded PEC films a single $T_{\mathrm{g}}$ event was observed (data not shown), which is an indication of the drug being molecularly dispersed in the polymer matrix. In contrast, embedded BSA had no relevant influence on the $T_{\mathrm{g}}$ of the investigated PEC films.

XRPD was performed for the PEC polymers and rifampicin-loaded PEC films (10 wt.\%) (Figure 1). All polymers (Figure 1A) and rifampicin-loaded polymer samples (Figure 1B) were amorphous, while unprocessed rifampicin powder alone was crystalline. This result supports the thermoanalytical measurements, where all samples showed no melting endotherm for rifampicin. BSA-loaded PEC films were also of amorphous nature (data not shown).

[insert Figure 1 here]

3.2 Polymer film degradation. Degradation studies of the PEC films were performed in the presence and absence of cholesterol esterase (Figure 2). This enzyme is expressed by several cells including macrophages [26] and pancreatic cells [27] and has been demonstrated to actively degrade PEC in vitro [16]. Polymer films showed clear signs of surface erosion in the presence of cholesterol esterase (no degradation in PBS without added cholesterol esterase). Interestingly, the degradation rate was shown to be dependent on the $M_{\mathrm{w}}$ of the employed polymer (Figure 2A).

[insert Figure 2 here]

Faster degradation was observed for higher $M_{\mathrm{w}}$ (PEC196, degradation half-life $\left(t_{1 / 2}\right)$ of $\sim 9$ d), whereas PEC85 revealed remarkably slower degradation rates (degradation $t_{1 / 2}$ of $\sim 14$ d). Figure 2B illustrates that the polymer $M_{\mathrm{w}}$ remained constant throughout the degradation 
study under both incubation conditions. Thus, the length of individual polymer chains remained constant while the film samples experienced relevant mass loss, indicating erosion of a fulllength polymer chain from the film.

This behavior is strikingly different from what is typically reported for bulk-eroding polymers. As an example, poly(lactide-co-glycolide) undergoes a mass loss and decrease in polymer $M_{\mathrm{w}}$ once in contact with aqueous media [22]. Shorter polymer chains (lower $M_{\mathrm{w}}$ ) generally tend to experience a quicker degradation process compared with longer polymer chains (higher $M_{\mathrm{w}}$ ). One possible explanation for the observed degradation rates for PEC films of different $M_{\mathrm{w}}$ could be attributed to differences in the individual polymer structure. As outlined by Acemoglu et al. [12], the synthesis of PEC results in the formation of both $\left(\mathrm{O}(\mathrm{CO}) \mathrm{OCH}_{2} \mathrm{CH}_{2}\right)^{-}$and $-\left(\mathrm{O}(\mathrm{CO})\left(\mathrm{OCH}_{2} \mathrm{CH}_{2}\right)_{\mathrm{x}}\right)^{-}$repeating units. Here, the $\left(\mathrm{O}(\mathrm{CO})\left(\mathrm{OCH}_{2} \mathrm{CH}_{2}\right)_{\mathrm{x}}\right)$ - units, which are thought to be selectively hydrolyzed during the aqueous thermal degradation process used to generate the lower $M_{\mathrm{w}}$ specimens of PEC, are more hydrophilic. Thus, PEC196 is expected to be the most hydrophilic polymer of the series. Accordingly, the polymer degradation by cholesterol esterase (and the accompanied rapid drug release profiles) showed an "inverse" dependency on $M_{\mathrm{w}}$. This hypothesis was challenged by incubating PEC196 and PEC85 with cholesterol esterase and comparing the morphology of the degraded films by means of SEM (Figure 3). As expected, a rough surface with pore formation was visible for PEC196 films indicating a relieved degradation by cholesterol esterase of this polymer. In contrast, the surface of PEC85 films was rather "smooth" over the time-course of incubation (only little difference was seen to freshly-prepared PEC films (Figure S5, Supplementary materials)). In this context, the polymer chain flexibility needs to be considered, where PEC196 is thought to relax ("healing" process of polymer surface) the slowest because of the higher $M_{\mathrm{w}}$ [28]. Thus, the surface of PEC85 remained "smoother" during enzyme degradation, due to less pronounced erosion and a higher rate for "repair" of the surface.

[insert Figure 3 here]

3.3 Drug release. The release of a small, rather hydrophobic drug and a large, hydrophilic protein was studied from the diverse PEC films (Figures 4-6). In the absence of cholesterol esterase, no relevant burst release of rifampicin $(<10 \%)$ was detected, indicating no relevant diffusional drug transport through the polymer matrix (Figure 4A). 
[insert Figure 4 here]

In contrast, a gradual rifampicin release from all investigated polymer films was obtained in the presence of cholesterol esterase, however, at substantial different release rates (Figure 4B). Here, PEC196 showed the fastest drug release rate followed by PEC174, PEC133, PEC110 and PEC85. PEC196 released $75 \%$ of its payload over $14 \mathrm{~d}$, while PEC85 delivered only $\sim 40 \%$ of the encapsulated rifampicin content.

The calculated $t_{1 / 2}$ values of PEC film degradation (Figure 2) and rifampicin release curves (Figure 4) in the presence of cholesterol esterase were plotted, where a linear correlation was obtained (Figure 5).

[insert Figure 5 here]

The slope of the resulting line of regression was $>1$, which is indicative for a slightly faster rifampicin release compared to what one would expect by a drug release process mediated by "simple" surface erosion.

In a second set of release experiments, the delivery of BSA was studied from PEC films in the absence and presence of cholesterol esterase (Figure 6). Without added cholesterol esterase, PEC196 experienced a considerably higher BSA release $(\sim 30-40 \%)$ compared to PEC85 (<10\%) (Figure 6A).

[insert Figure 6 here]

When incubated with cholesterol esterase, a progressive BSA release was seen from the investigated PEC196 and PEC85 films, again at substantial different release rates (Figure 6B). PEC196 delivered the complete BSA payload within the incubation period. In contrast, PEC 85 showed a slower BSA release profile with $\sim 60 \%$ of the encapsulated amount delivered after $14 \mathrm{~d}$. As discussed above (Figures 2 and 3), this elevated BSA release rate observed for PEC196 is likely attributed to the difference in polymer degradation by cholesterol esterase, leading to a distinct drug release profile $[15,16,19]$.

Overall, the release of rifampicin and BSA from PEC films of different $M_{\mathrm{w}}$ matched the observations made during the film degradation study, where the highest polymer erosion rate was seen for the PEC with the highest $M_{\mathrm{w}}$ (i.e., PEC196). Thus, the $M_{\mathrm{w}}$-dependent erosion of PEC could be used to tailor a desired release profile for both rather small drugs and 
biomacromolecules. Here, especially rifampicin revealed remarkably linear (predictable) release kinetics. It was further demonstrated in vitro, that the drug delivery from PEC was initiated by an enzyme-specific surface erosion process of the delivery vehicle, which can be considered as a prerequisite for an on-demand drug delivery to a desired cell population or tissue/organ within the body. Bulk-eroding polymers, such as conventional polyesters, share none of these auspicious features [5, 22, 29].

3.4 Polymer film degradation by macrophages and in vivo. Degradation studies in cell culture and in vivo underlined the unique potential of PEC as biomaterial for prolonged drug delivery applications (Figures 7-10). Polymer films, which were incubated with RAW264.7 macrophages, showed rapid mass loss as a function of the employed $M_{\mathrm{w}}$ with degradation $t_{1 / 2}$ of $\sim 3$ and $\sim 5 \mathrm{~d}$ for PEC196 and PEC 85, respectively (Figure 7A). During the incubation process, no relevant change of polymer $M_{\mathrm{w}}$ was detected (Figure 7B).

\section{[insert Figure 7 here]}

No degradation occurred in plain cell culture medium (i.e., no mass loss, change of polymer $M_{\mathrm{w}}$ or film surface (data not shown)), while the morphology of the freshly-prepared PEC films (Figure S5, Supplementary materials) changed dramatically when incubated with macrophages (Figure 8). As it can be seen from the SEM images, the surface of degraded PEC196 and PEC85 films revealed obvious difference with respect to the porous microstructure. PEC196 films showed mainly numerous small pores (with a cross-section $<10$ $\mu \mathrm{m})$ as well as large holes (cross section $>200 \mu \mathrm{m}$ ), where the macrophages had fully penetrated the polymer film. In contrast, degraded PEC85 films were characterized by an overall lower number of pores. Besides bigger holes, which matched the size of RAW264.7 macrophages (10-20 $\mu \mathrm{m}$ in diameter), also smaller pores below the size of the cells were visible. These findings further indicated that the polymer structure of PEC196 films was easier to penetrate for the RAW264.7 macrophage cell line.

\section{[insert Figure 8 here]}

Thus, the process by which the polymer films were degraded by RAW264.7 macrophages (i.e., surface erosion) was in general agreement with the observations from the 
studies with cholesterol esterase (Figures 2 and 3). However, the overall rate of PEC degradation was more pronounced in cell culture (Figure 7). One possible explanation for the distinct extent of surface erosion could be the higher local concentration of distinct degrading enzymes (and/or radicals) of RAW264.7 macrophages, which are found in close proximity to the polymer film, compared to "simple" cholesterol esterase solution.

Degradation studies of polymer films were also performed after subcutaneous implantation in rats (Figures 9 and 10). PEC196 and PEC85 films were rapidly eroded in vivo (Figure 9A), with no significant change of $M_{\mathrm{w}}$ over the time-course of implantation (Figure 9B). The mechanism (i.e., surface erosion) and overall rate of polymer degradation in vivo were similar to the studies conducted with cholesterol esterase (Figure 2) and RAW264.7 macrophages (Figure 7).

[insert Figure 9 here]

When comparing the time-course of PEC196 and PEC85 film morphology during in vivo degradation (Figure 10), the surface structure of PEC196 and PEC85 and thus, the specific surface erosion mechanism by which the two tested polymers were degraded, was strikingly different. As seen for cholesterol esterase-mediated (Figure 3) and RAW264.7 macrophagemediated (Figure 8) polymer film degradation, numerous pores were formed on the surface of PEC196, which then transformed to a "rough" polymer interface with time.

\section{[insert Figure 10 here]}

In contrast, the surface of PEC85 films was rather "smooth", characterized by less, but larger scoop-like pores, which underwent significant progression during the time-course of in vivo degradation. Previous studies have reported that the biodegradation of PEC in vivo was mainly triggered by immuno-competent cells, which rapidly attached to the polymer surface after implantation $[11,14]$. Released enzymes (and/or radicals) then initiated the surface degradation process. Here, a close proximity of macrophages to the PEC surface was considered essential [14]. However, these general findings cannot explain the observed discrepancy of surface morphology for PEC196 and PEC85 films during in vitro and in vivo degradation and its general implication on an accompanied drug release process. Besides the faster rate of surface erosion observed for PEC196, the formation of many "small" pores and a "rough" film surface during biodegradation (increase in surface area) would cause an even 
faster, surface erosion-controlled drug release, an issue that clearly deserves further clarification/investigations.

\section{CONCLUSIONS}

A biomaterial with potential for an on-demand drug release would add significant benefit to the biomedical field. Controlled drug delivery vehicles, which could defer drug release until reaching a certain target and/or are "activated" by specific stimuli (e.g., enzymes or cells) would limit systemic drug exposure and drug dose, and consequently reduce side effects. Among the large number of natural and synthetic polymers, PEC is one of such promising biomaterials, which undergoes enzyme- and cell-specific surface erosion in vitro and in vivo. Consequently, delivery systems made from PEC result in predictable drug release patterns. In this respect, the current study identified the molecular weight of PEC as an essential parameter to control the spatial and temporal drug release from the employed delivery system. Overall, surface-eroding PEC is thought to result in a suitable on-demand drug release to the desired site of action avoiding high and uncontrollable systemic drug levels.

\section{ACKNOWLEDGEMENTS}

The authors wish to thank the "Danish Council for Independent Research" [grant no. 12-131927] and the Lundbeck Foundation [grant no. R218-2016-1323] for financial support of this project and the Innovation Fund Denmark [grant no. 041-2010-3] for financial support of equipment used. We also wish to thank Maria Diana Lessøe Pedersen for her support with cell culture studies and Prof. Hanne Mørck Nielsen for supporting and providing scientific input to the project. Furthermore, the Institut Galien (Université Paris-Sud, France) is gratefully acknowledged for providing NMR and GPC facilities, and the Core Facility for Integrated Microscopy (University of Copenhagen) is acknowledged for SEM facilities and support.

\section{REFERENCES}


[1] M.J. Webber, E.A. Appel, E.W. Meijer, R. Langer, Supramolecular biomaterials, Nat. Mater., 15 (2015) 13-26.

[2] N. Kamaly, B. Yameen, J. Wu, O.C. Farokhzad, Degradable controlled-release polymers and polymeric nanoparticles: Mechanisms of controlling drug release., Chem. Rev., 116 (2016) 2602-2663.

[3] H.K. Makadia, S.J. Siegel, Poly lactic-co-glycolic acid (PLGA) as biodegradable controlled drug delivery carrier, Polymers, 3 (2011) 1377-1397.

[4] D.N. Kapoor, A. Bhatia, R. Kaur, R. Sharma, G. Kaur, S. Dhawan, PLGA: a unique polymer for drug delivery, Ther. Deliv., 6 (2015) 41-58.

[5] A.N. Ford Versypt, D.W. Pack, R.D. Braatz, Mathematical modeling of drug delivery from autocatalytically degradable PLGA microspheres-a review, J. Controlled Release, 165 (2013) 29-37.

[6] A.G. Ding, A. Shenderova, S.P. Schwendeman, Prediction of microclimate pH in poly(lactic-co-glycolic acid) films, J. Am. Chem. Soc., 128 (2006) 5384-5390.

[7] S. Fredenberg, M. Wahlgren, M. Reslow, A. Axelsson, The mechanisms of drug release in poly (lactic-co-glycolic acid)-based drug delivery systems - a review, Int. J. Pharm., 415 (2011) 34-52.

[8] C.F. van der Walle, G. Sharma, M. Ravi Kumar, Current approaches to stabilising and analysing proteins during microencapsulation in PLGA, Expert Opin. Drug Deliv., 6 (2009) 177-186.

[9] S.P. Schwendeman, R.B. Shah, B.A. Bailey, A.S. Schwendeman, Injectable controlled release depots for large molecules, J. Controlled Release, 190 (2014) 240-253.

[10] J. Siepmann, F. Soiepmann, Mathematical modeling of drug delivery, Int . J. Pharm., 364 (2008) 328-343.

[11] M. Dadsetan, E.M. Christenson, F. Unger, M. Ausborn, T. Kissel, A. Hiltner, J.M. Anderson, In vivo biocompatibility and biodegradation of poly(ethylene carbonate), J. Controlled Release, 93 (2003) 259-270.

[12] M. Acemoglu, F. Nimmerfall, S. Bantle, G.H. Stoll, Poly(ethylene carbonate)s, part I: Syntheses and structural effects on biodegradation, J. Controlled Release, 49 (1997) 263-276.

[13] L.A. Cornacchione, B. Qi, J. Bianco, Z. Zhou, B.G. Amsden, Photo-cross-linked poly(ethylene carbonate) elastomers: synthesis, in vivo degradation, and determination of in vivo degradation mechanism, Biomacromolecules, 13 (2012) 3099-3107. 
[14] G.H. Stoll, F. Nimmerfall, M. Acemoglu, D. Bodmer, S. Bantle, I. Müller, A. Mahl, M. Kolopp, K. Tullberg, Poly(ethylene carbonate)s, part II: degradation mechanisms and parenteral delivery of bioactive agents, J. Controlled Release, 76 (2001) 209-225.

[15] Y. Liu, A. Kemmer, K. Keim, C. Curdy, H. Petersen, T. Kissel, Poly(ethylene carbonate) as a surface-eroding biomaterial for in situ forming parenteral drug delivery system: a feasibility study, Eur. J. Pharm. Biopharm., 76 (2010) 222-229.

[16] D. Chu, C. Curdy, B. Riebesehl, Y. Zhang, M. Beck-Broichsitter, T. Kissel, Enzymeresponsive surface erosion of poly (ethylene carbonate) for controlled drug release, Eur. J. Pharm. Biopharm., 85 (2013) 1232-1237.

[17] D. Chu, M. Beck-Broichsitter, C. Curdy, B. Riebesehl, T. Kissel, Feasibility of macrophage mediated on-demand drug release from surface eroding poly(ethylene carbonate), Int. J. Pharm., 465 (2014) 1-4.

[18] R.A. Siegel, Stimuli sensitive polymers and self regulated drug delivery systems: a very partial review, J. Controlled Release, 190 (2014) 337-351.

[19] D. Chu, C. Curdy, B. Riebesehl, M. Beck-Broichsitter, T. Kissel, In situ forming parenteral depot systems based on poly(ethylene carbonate): effect of polymer molecular weight on model protein release., Eur. J. Pharm. Biopharm., 85 (2013) 1245-1249.

[20] M. Beck-Broichsitter, T. Schmehl, T. Gessler, W. Seeger, T. Kissel, Development of a biodegradable nanoparticle platform for sildenafil: formulation optimization by factorial design analysis combined with application of charge-modified branched polyesters, J. Controlled Release, 157 (2012) 469-477.

[21] A. Bohr, J.J. Water, Y. Wang, L. Arnfast, M. Beck-Broichsitter, Potential of surfaceeroding poly(ethylene carbonate) for drug delivery to macrophages, Int . J. Pharm., 511 (2016) 814-820.

[22] Y. Xu, C.S. Kim, D.M. Saylor, D. Koo, Polymer degradation and drug delivery in PLGAbased drug-polymer applications: A review of experiments and theories, J. Biomed. Mater. Res. B, (2016) doi: 10.1002/jbm.b.33648.

[23] T.G. Fox, P.J. Flory, Second-order transition temperatures and related properties of polystyrene, J. Appl. Phys., 21 (1950) 581-591.

[24] I.M. Kalogeras, A novel approach for analyzing glass-transition temperature vs. composition patterns: Application to pharmaceutical compound + polymer systems, Eur. J. Pharm. Sci., 42 (2011) 470-483. 
[25] S.E. Gilchrist, D.L. Rickard, K. Letchford, D. Needham, H.M. Burt, Phase separation behavior of fusidic acid and rifampicin in PLGA microspheres, Mol. Pharm., 9 (2012) 14891501.

[26] M.S. Brown, J.L. Goldstein, A receptor-mediated pathway for cholesterol homeostasis, Science, 232 (1986) 34-47.

[27] Y. Huang, D.Y. Hui, Cholesterol esterase biosynthesis in rat pancreatic AR42J cells. Posttranscriptional activation by gastric hormones, J. Biol. Chem., 266 (1991) 6720-6725.

[28] J.M. Mazzara, M.A. Balagna, M.D. Thouless, S.P. Schwendeman, Healing kinetics of microneedle-formed pores in PLGA films, J. Controlled Release, 171 (2013) 172-177.

[29] J.M. Anderson, M.S. Shive, Biodegradation and biocompatibility of PLA and PLGA microspheres, Adv. Drug Deliv. Rev., 28 (1997) 5-24. 


\section{Figure legends}

Figure 1. XRPD patterns of PEC polymers (A), rifampicin powder and rifampicin-loaded PEC films (B).

Figure 2. Degradation kinetics (remaining film mass (A) and remaining polymer $M_{\mathrm{w}}(\mathrm{B})$ ) of PEC films in the absence (open symbols) and presence (filled symbols) of cholesterol esterase. No SD bars are shown, if the SD fell into the symbol. The asterisks denote statistically significant difference compared to PEC85. For an interpretation of the color code, readers are referred to Figure 1.

Figure 3. SEM images of PEC films incubated with cholesterol esterase for $5 \mathrm{~d}$.

Figure 4. In vitro drug release profiles from rifampicin-loaded PEC films in the absence (A) and presence (B) of cholesterol esterase. No SD bars are shown, if the SD fell into the symbol. The asterisks denote statistically significant difference compared to PEC85. For an interpretation of the color code, readers are referred to Figure 1.

Figure 5. Correlation of polymer degradation of (Figure 2) and drug release from (Figure 4) rifampicin-loaded PEC films. The straight line represents a linear fit of the experimental data $\left(R^{2}=0.96\right)$. For an interpretation of the color code, readers are referred to Figure 1.

Figure 6. In vitro protein release profiles from BSA-loaded PEC films in the absence (A) and presence (B) of cholesterol esterase. No SD bars are shown, if the SD fell into the symbol. The asterisks denote statistically significant difference compared to PEC85. For an interpretation of the color code, readers are referred to Figure 1.

Figure 7. Degradation kinetics (remaining film mass (A) and remaining polymer $M_{\mathrm{w}}(\mathrm{B})$ ) of PEC films incubated with RAW264.7 macrophages. No SD bars are shown, if the SD fell into 
the symbol. The asterisks denote statistically significant difference compared to PEC85. For an interpretation of the color code, readers are referred to Figure 1.

Figure 8. SEM images of PEC196 and PEC85 films incubated with RAW264.7 macrophages for $5 \mathrm{~d}$. Scale bars $=100 \mu \mathrm{m}$.

Figure 9. Degradation kinetics (remaining film mass (A) and remaining polymer $M_{\mathrm{w}}(\mathrm{B})$ ) of PEC films implanted in rats. Values are presented as the mean $\pm \operatorname{SD}(n \geq 6)$. No SD bars are shown, if the SD fell into the symbol. The asterisks denote statistically significant difference compared to PEC85. For an interpretation of the color code, readers are referred to Figure 1.

Figure 10. SEM images of the time-course of PEC196 and PEC85 film degradation after implantation in rats. Scale bars $=100 \mu \mathrm{m}$. 


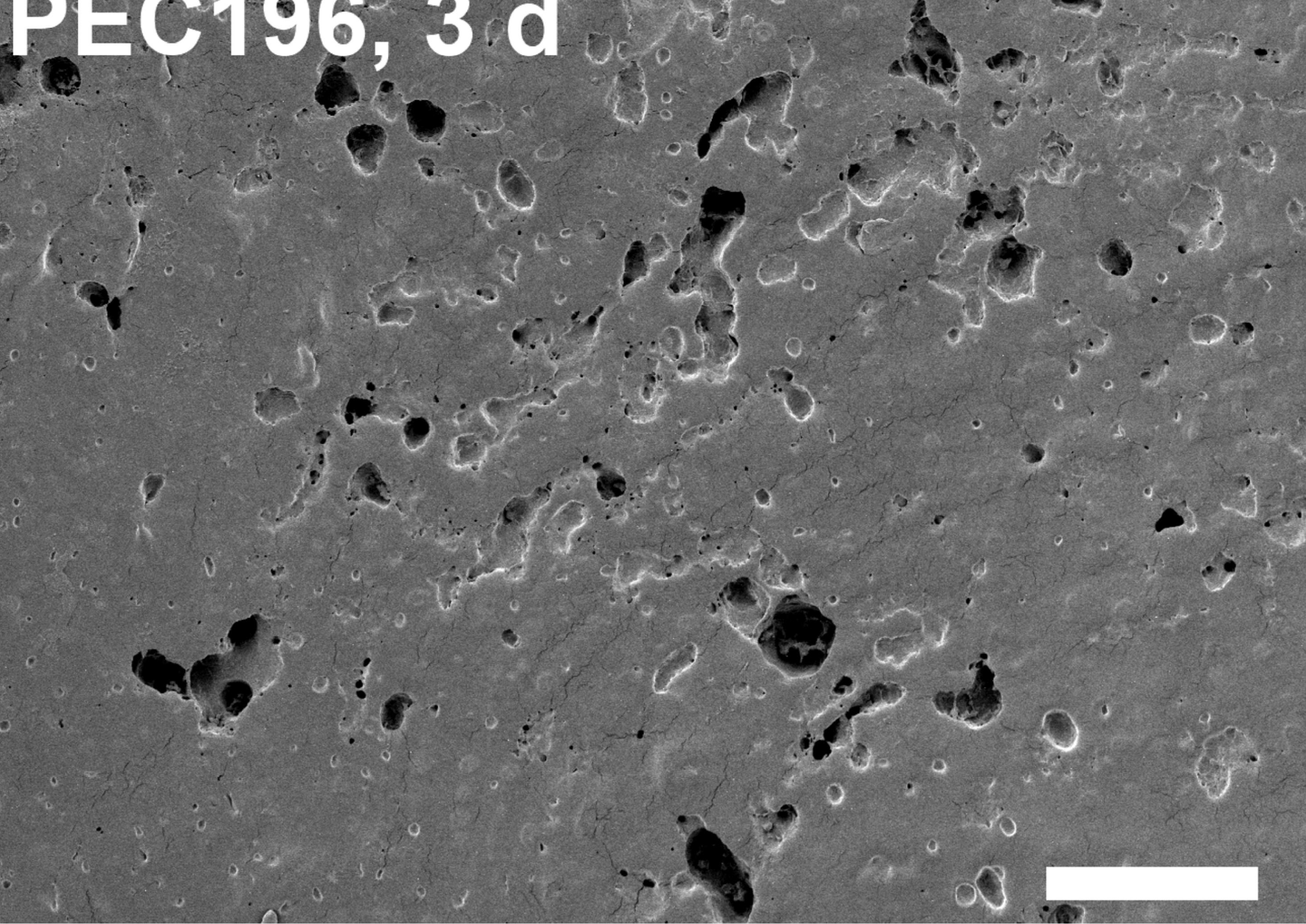




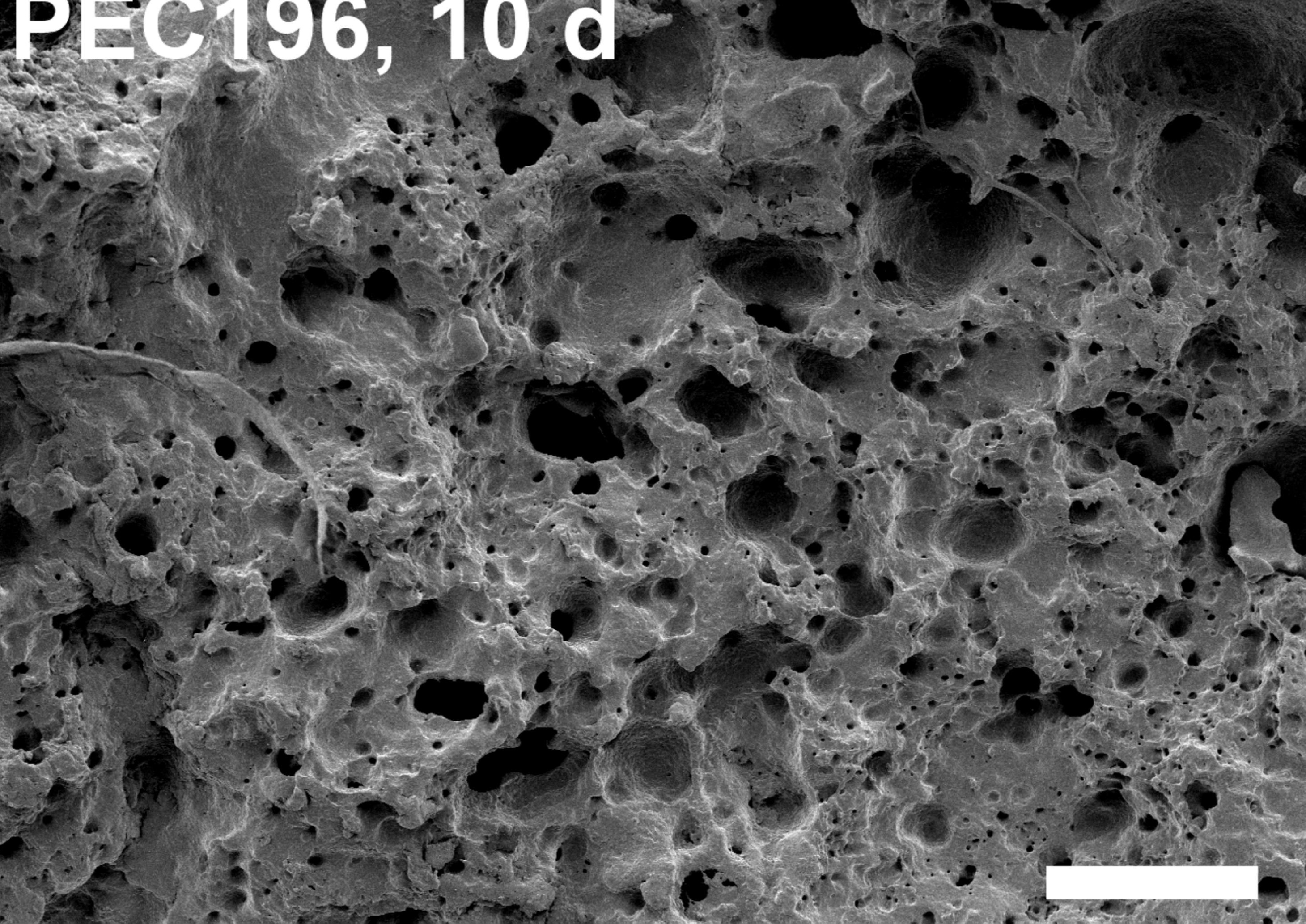




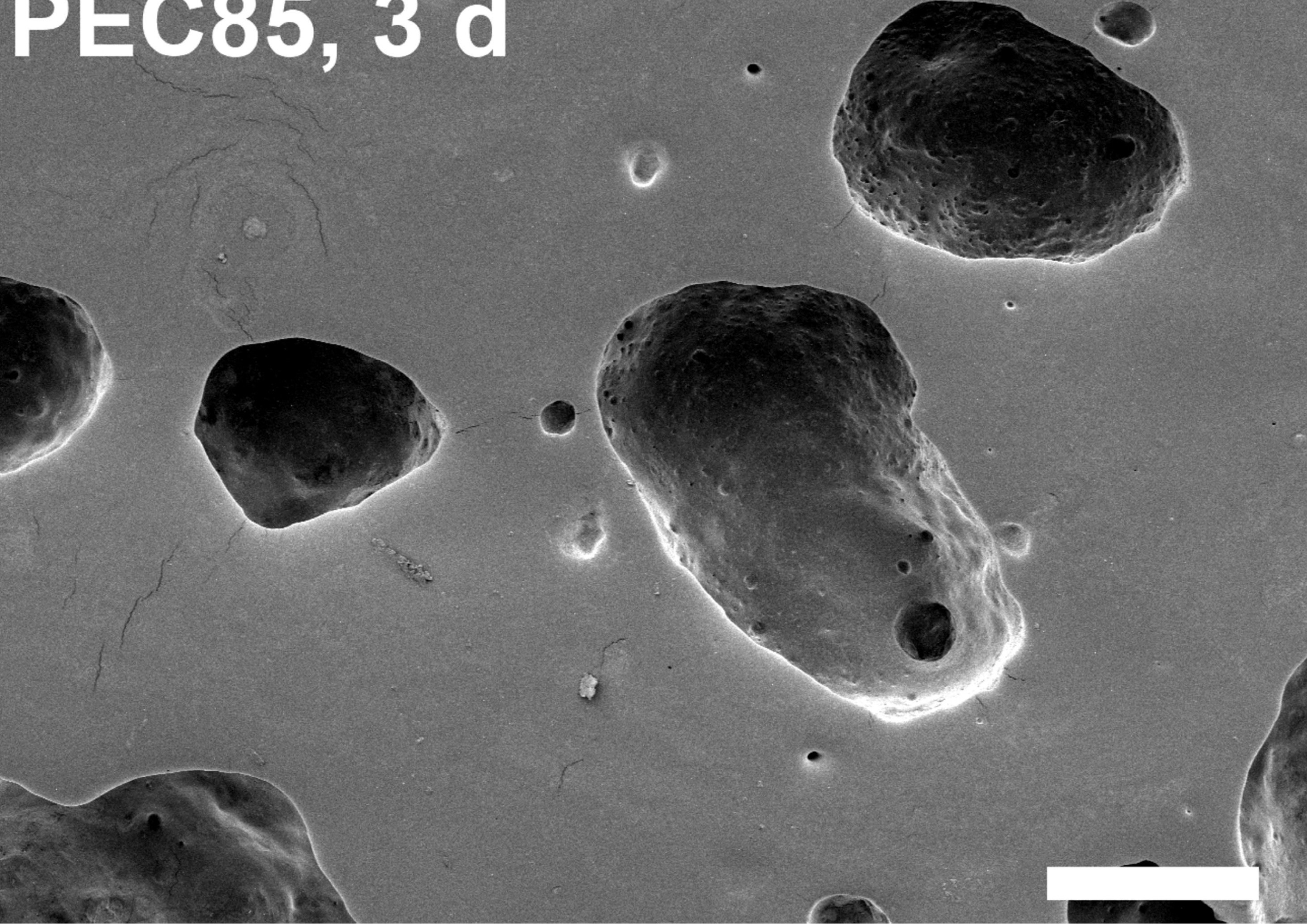


$P=C-196$, a d
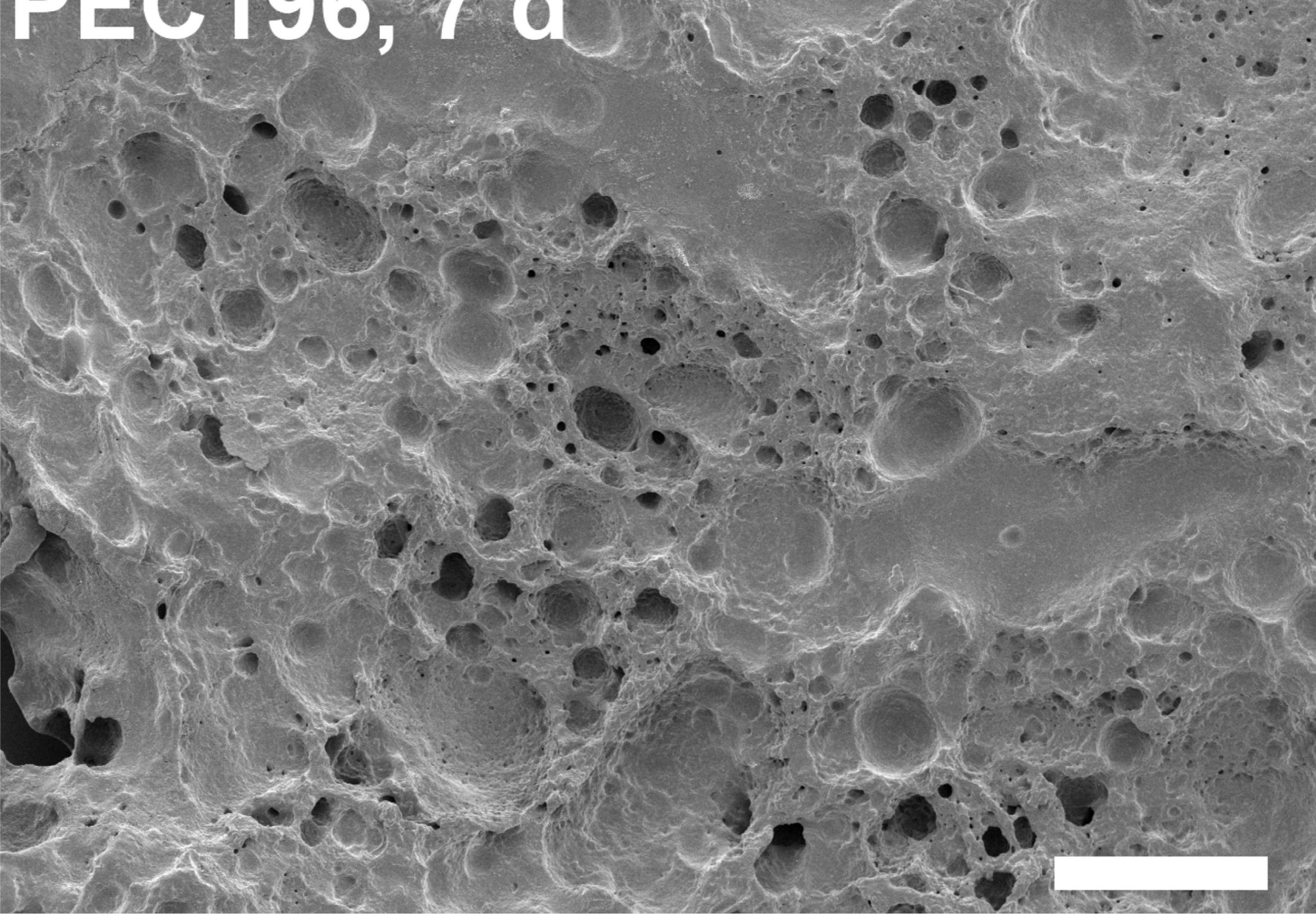


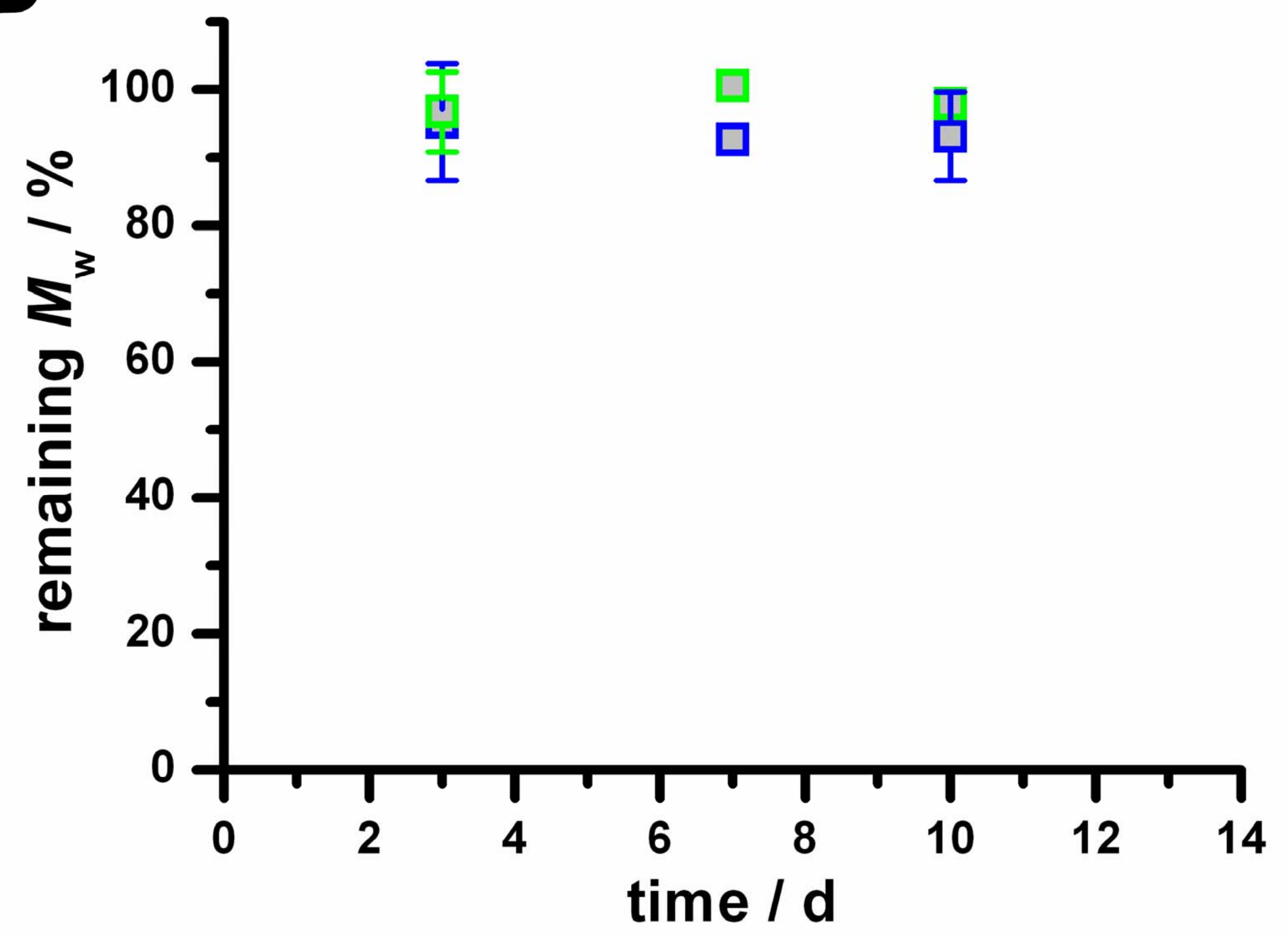




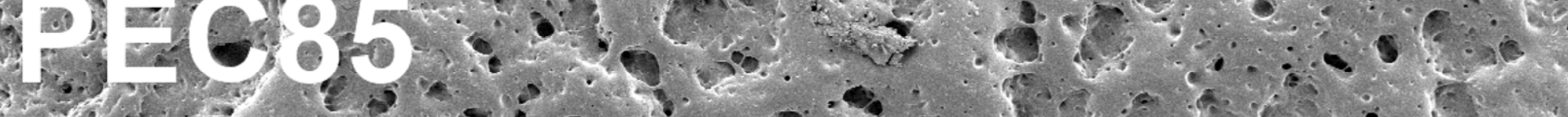

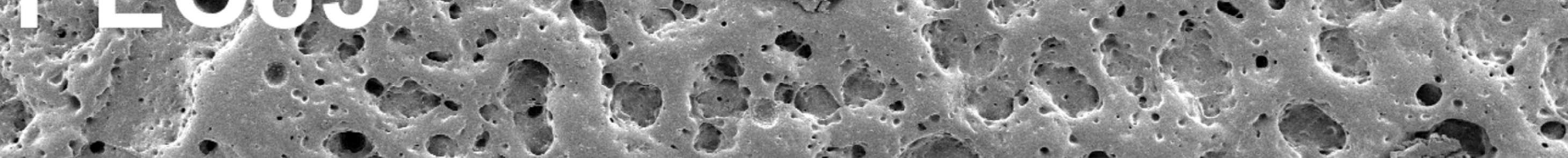

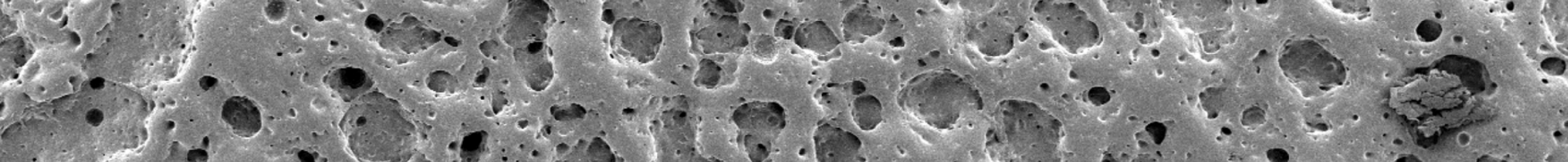

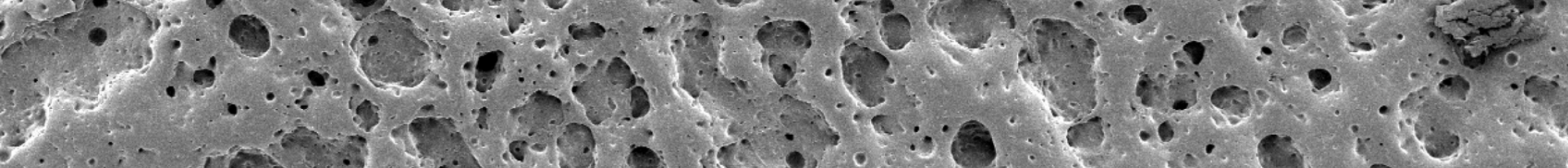

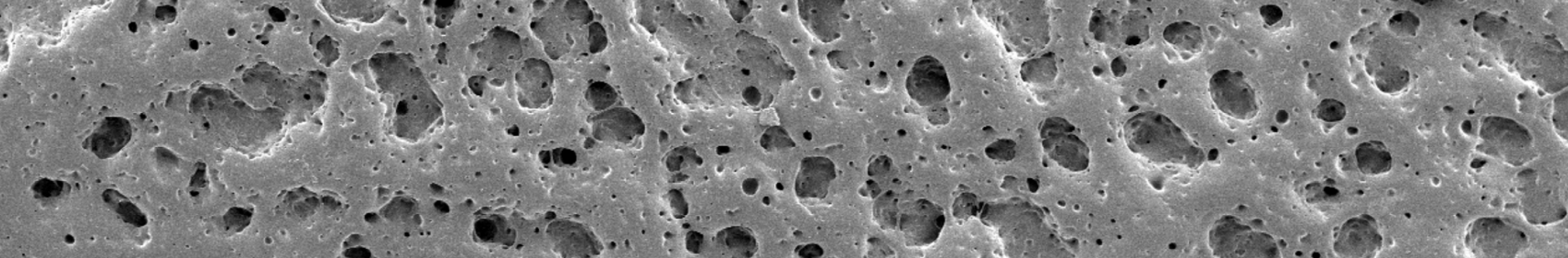

20.0 .09

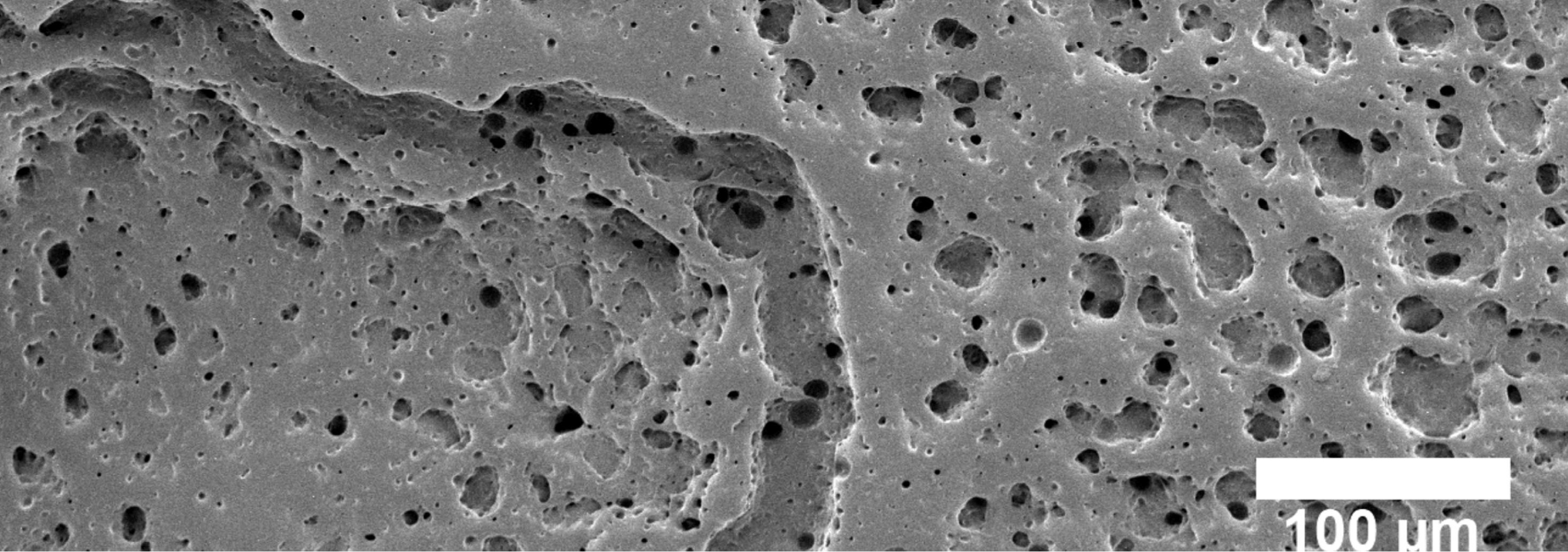




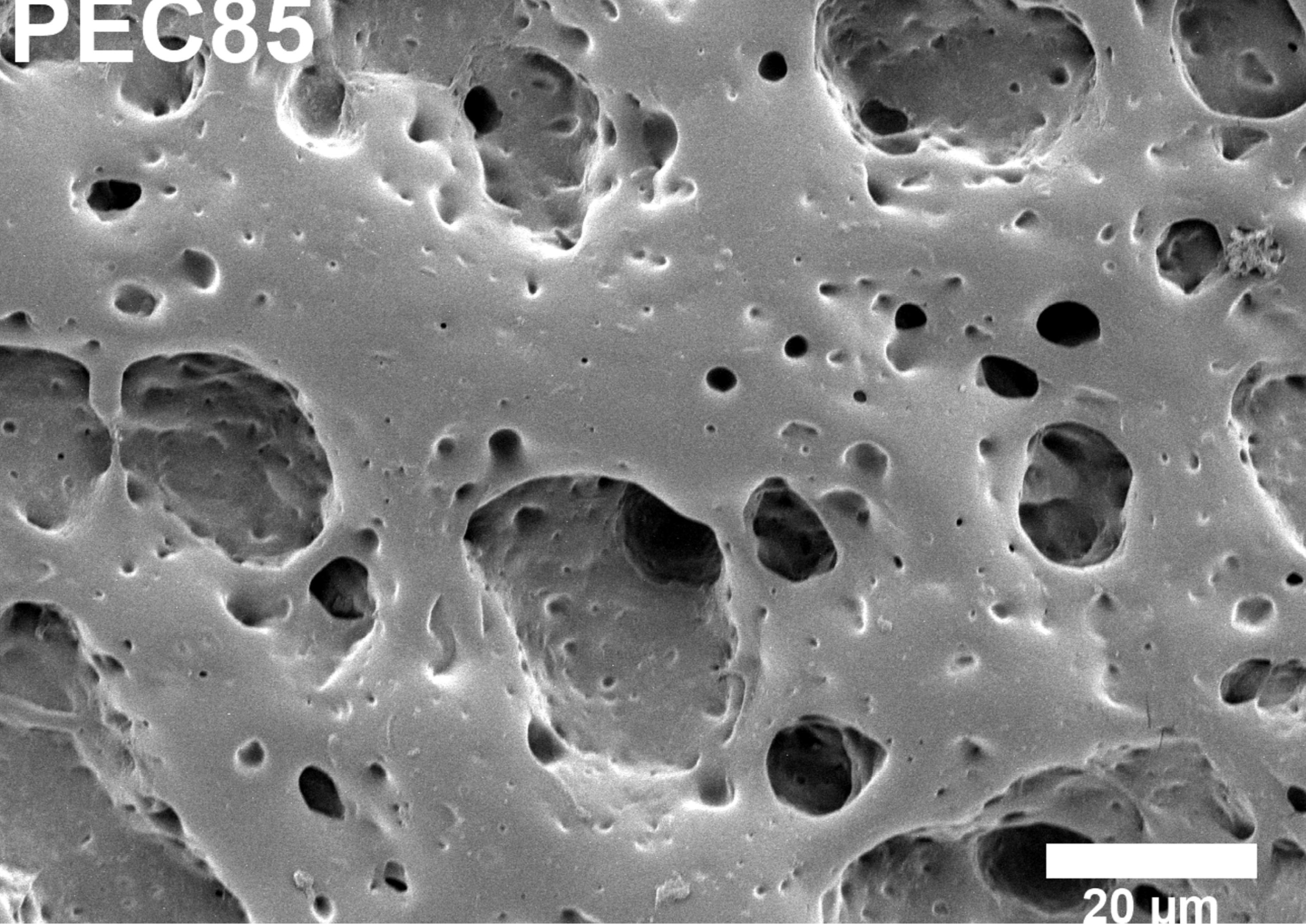




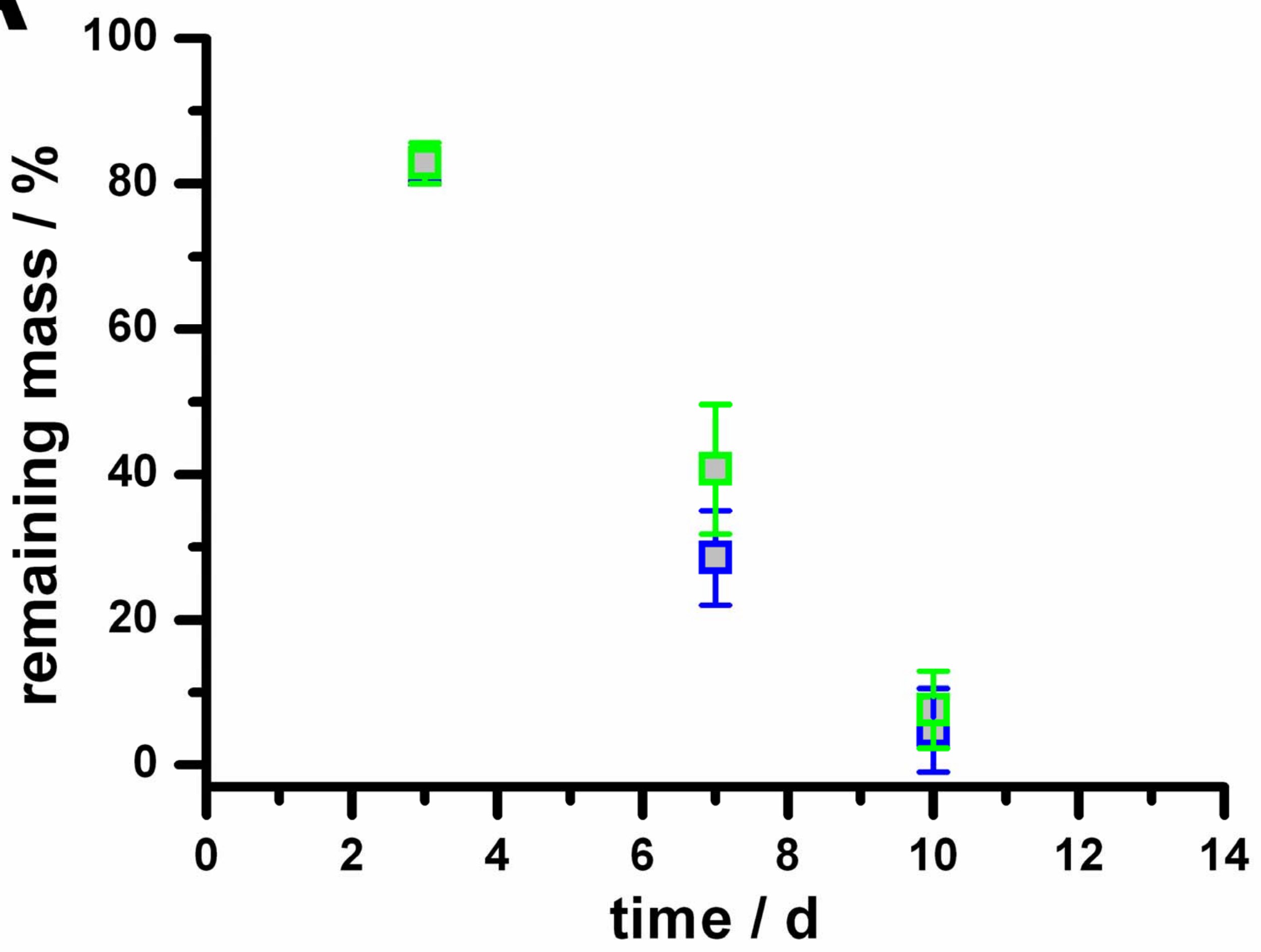




\section{PEC196}

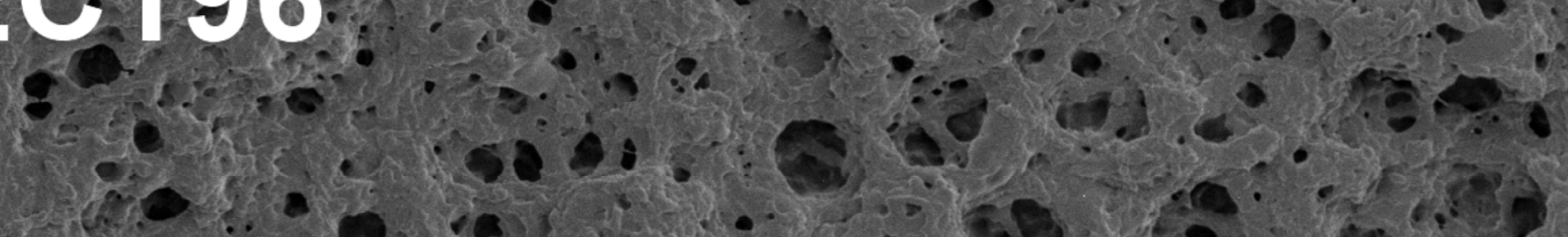

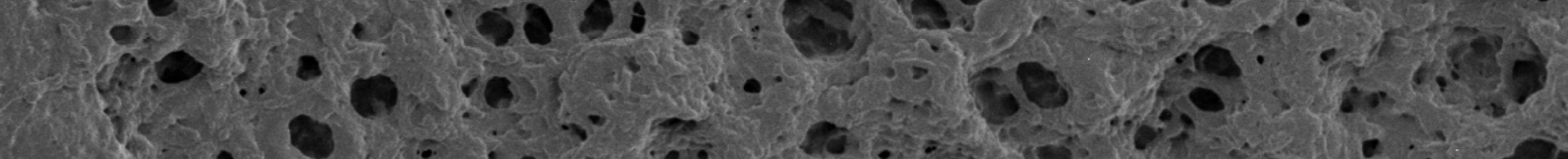
$10: 5: 60 \div 9$

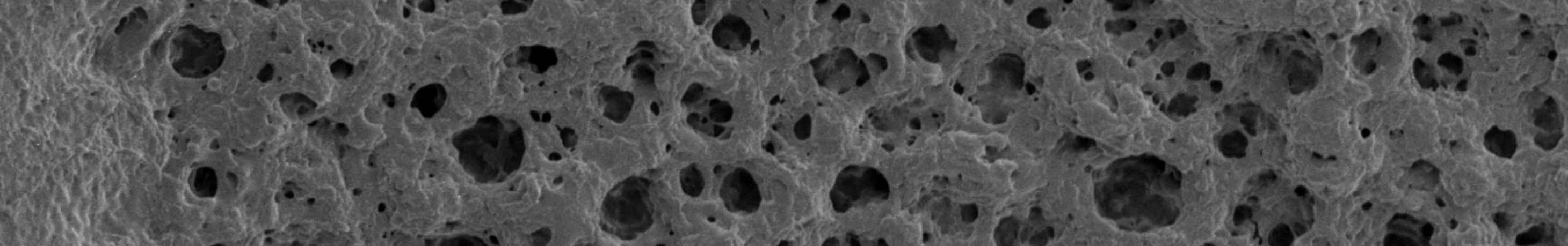

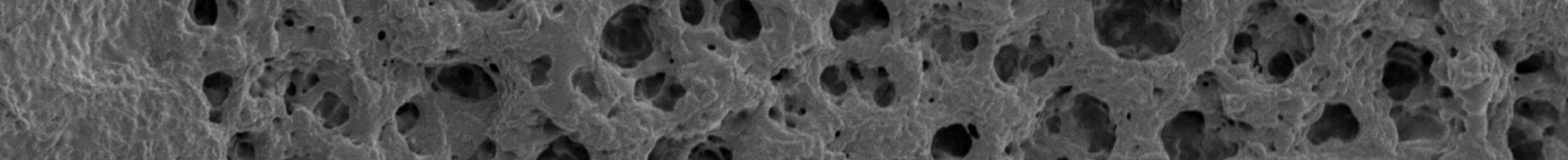

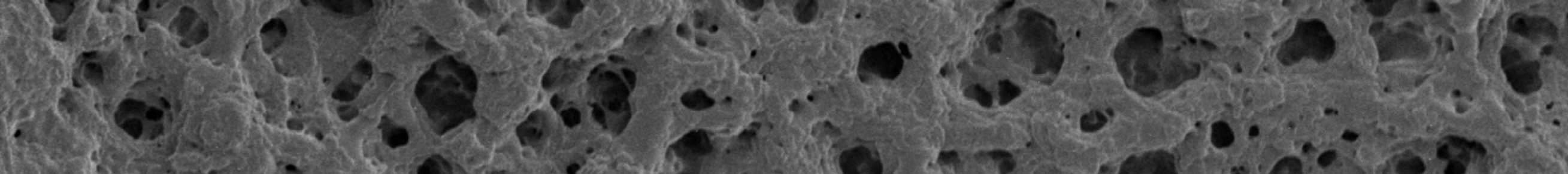
feilis 


\section{PEC196}

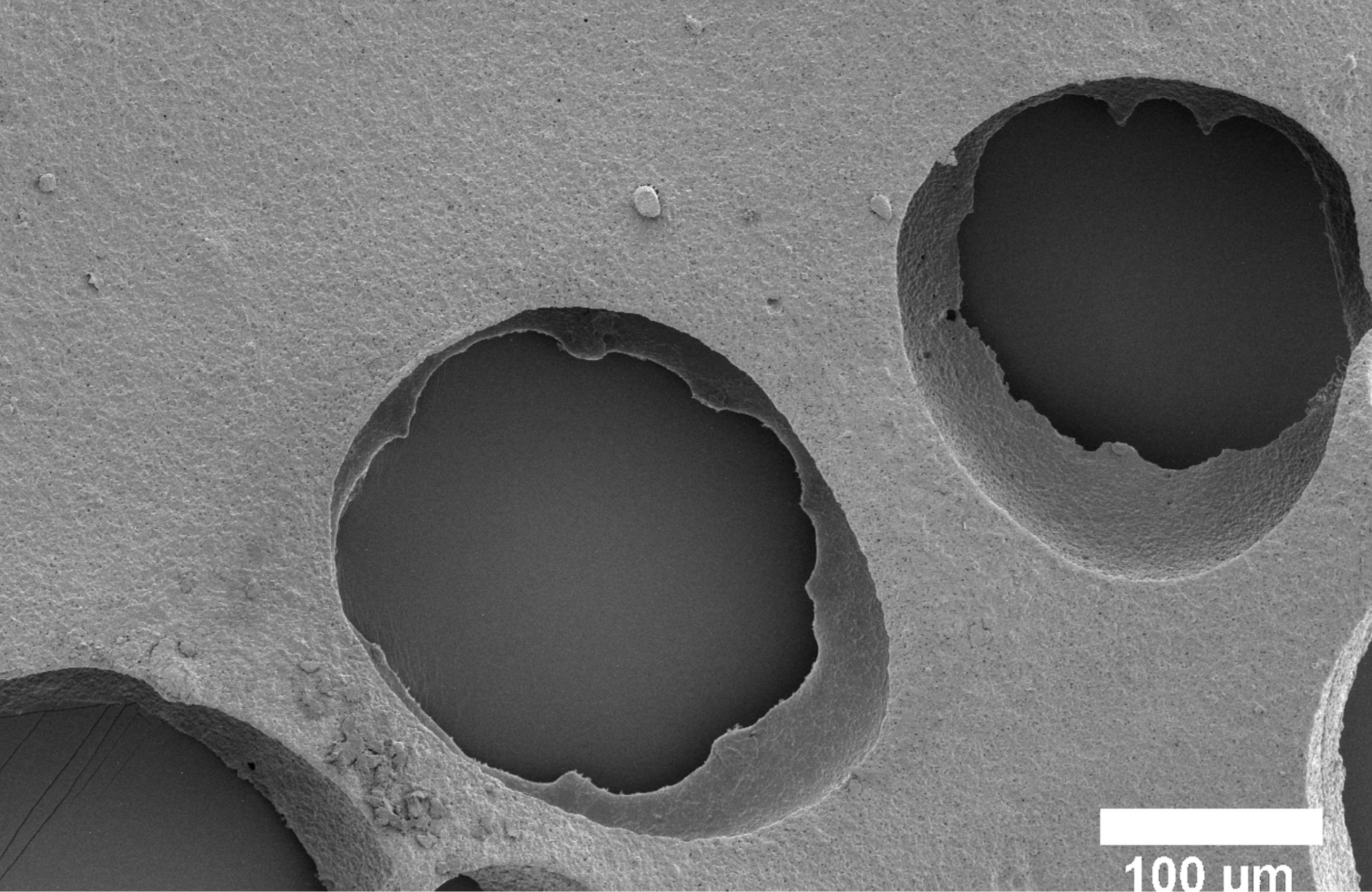


rec85, I $\therefore \therefore \therefore$ $\therefore$ $y^{3}$ 1

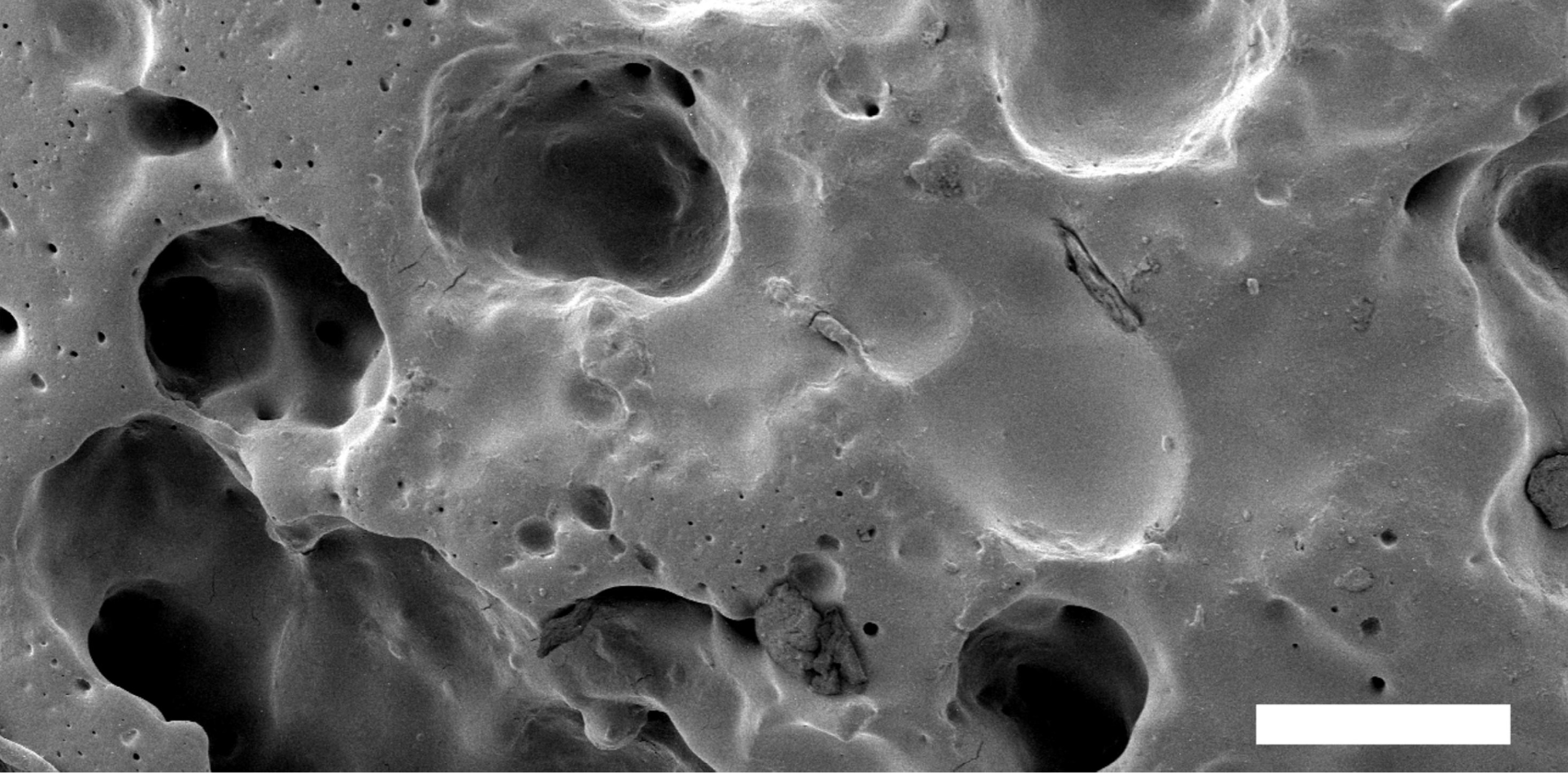




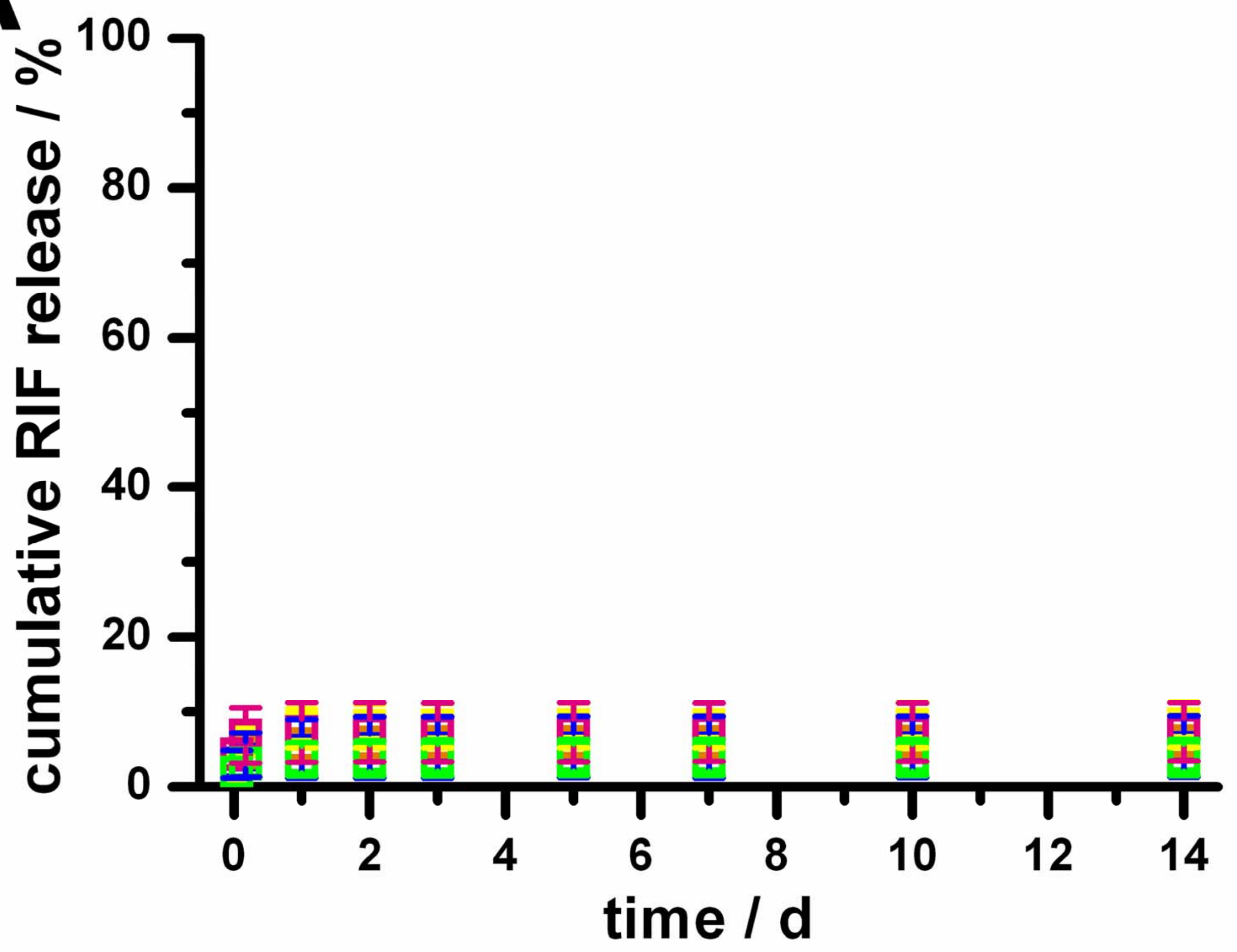




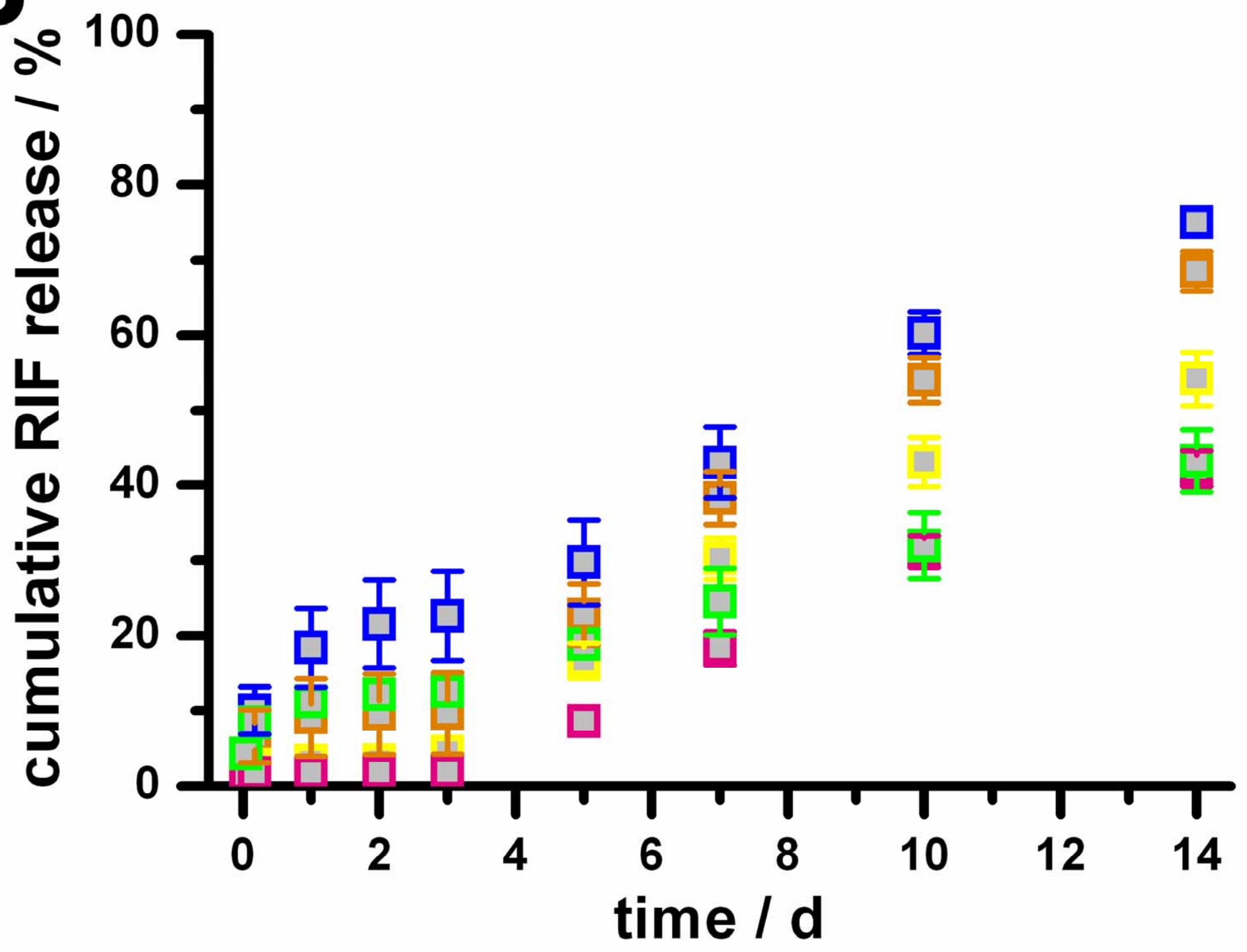




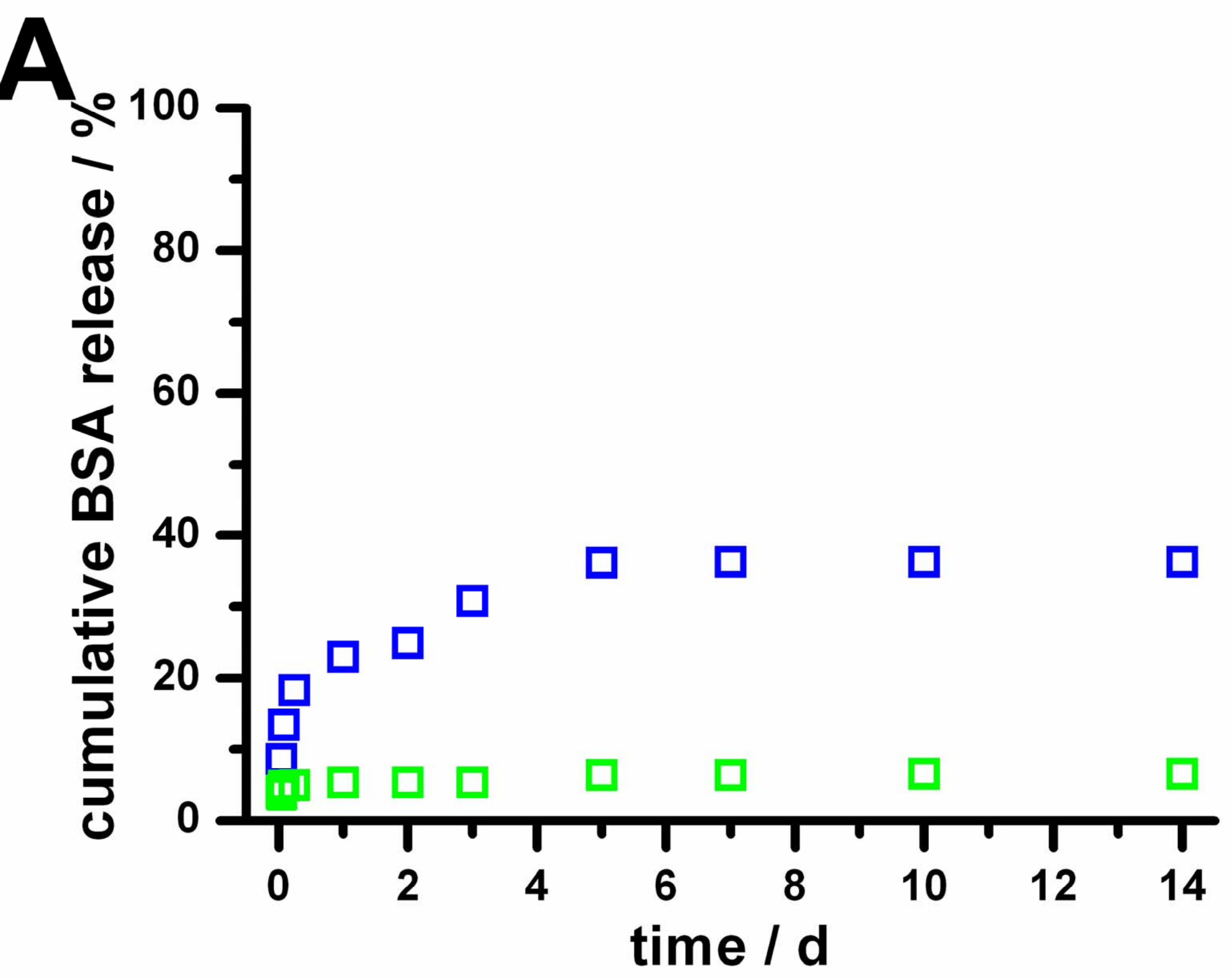




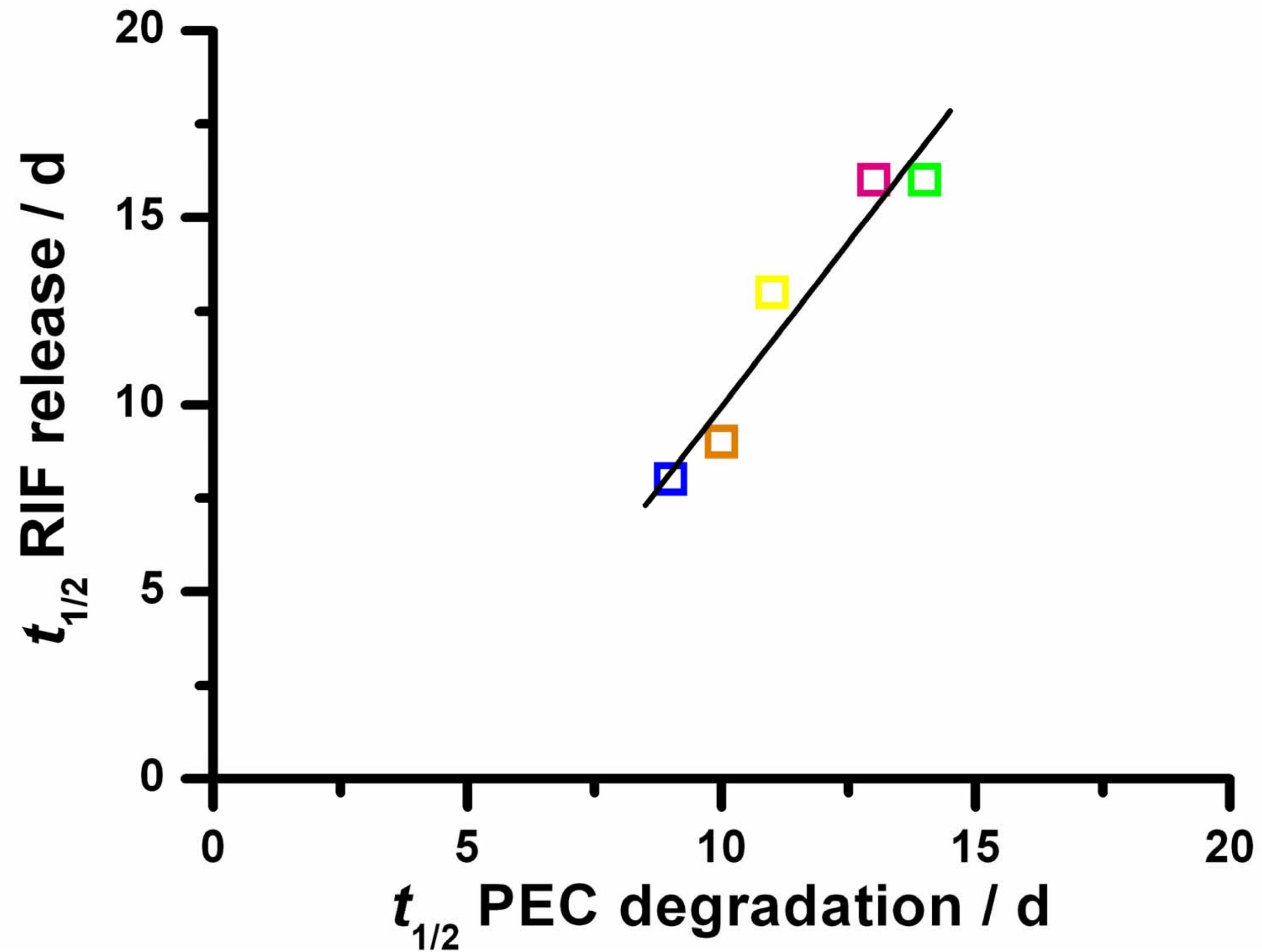




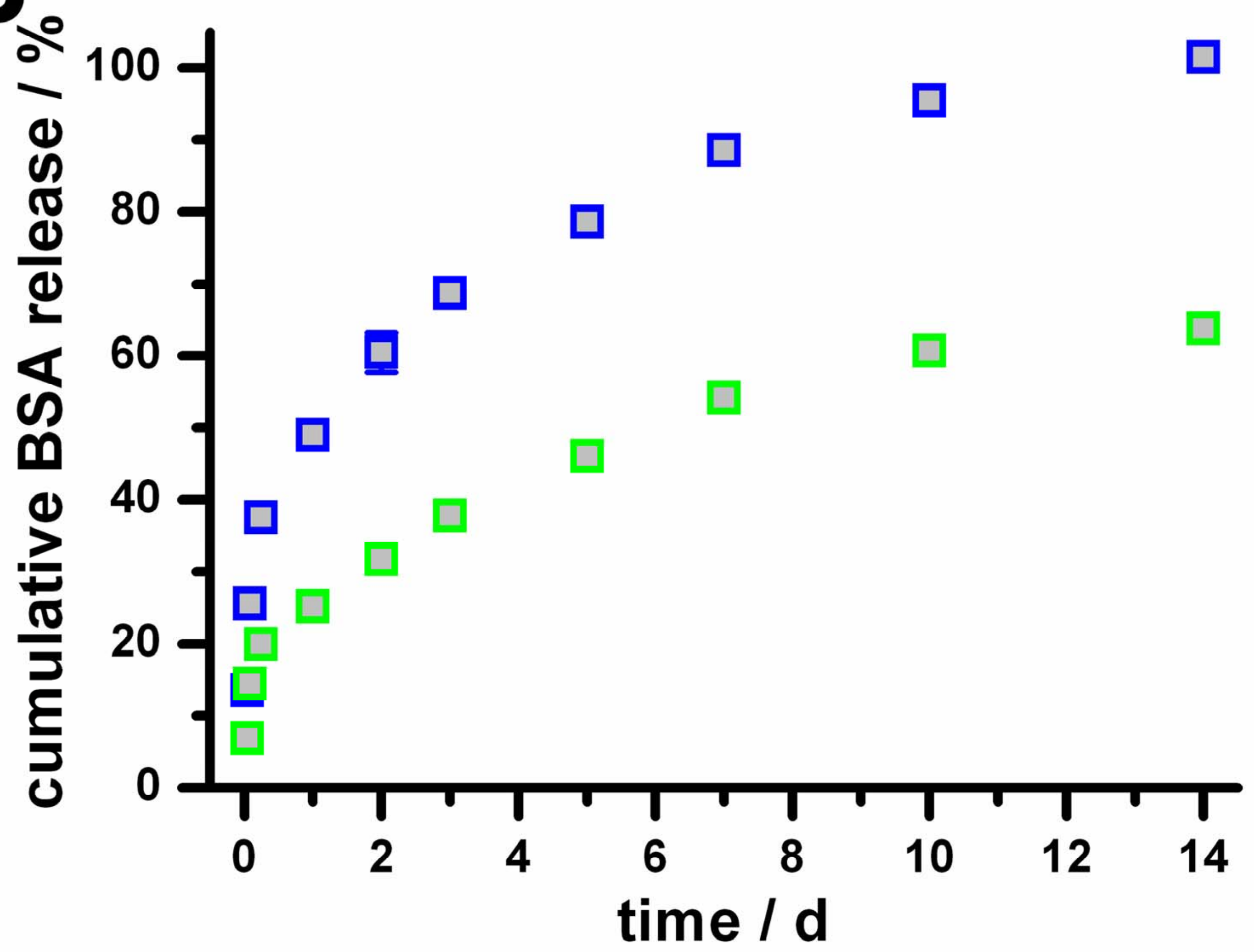




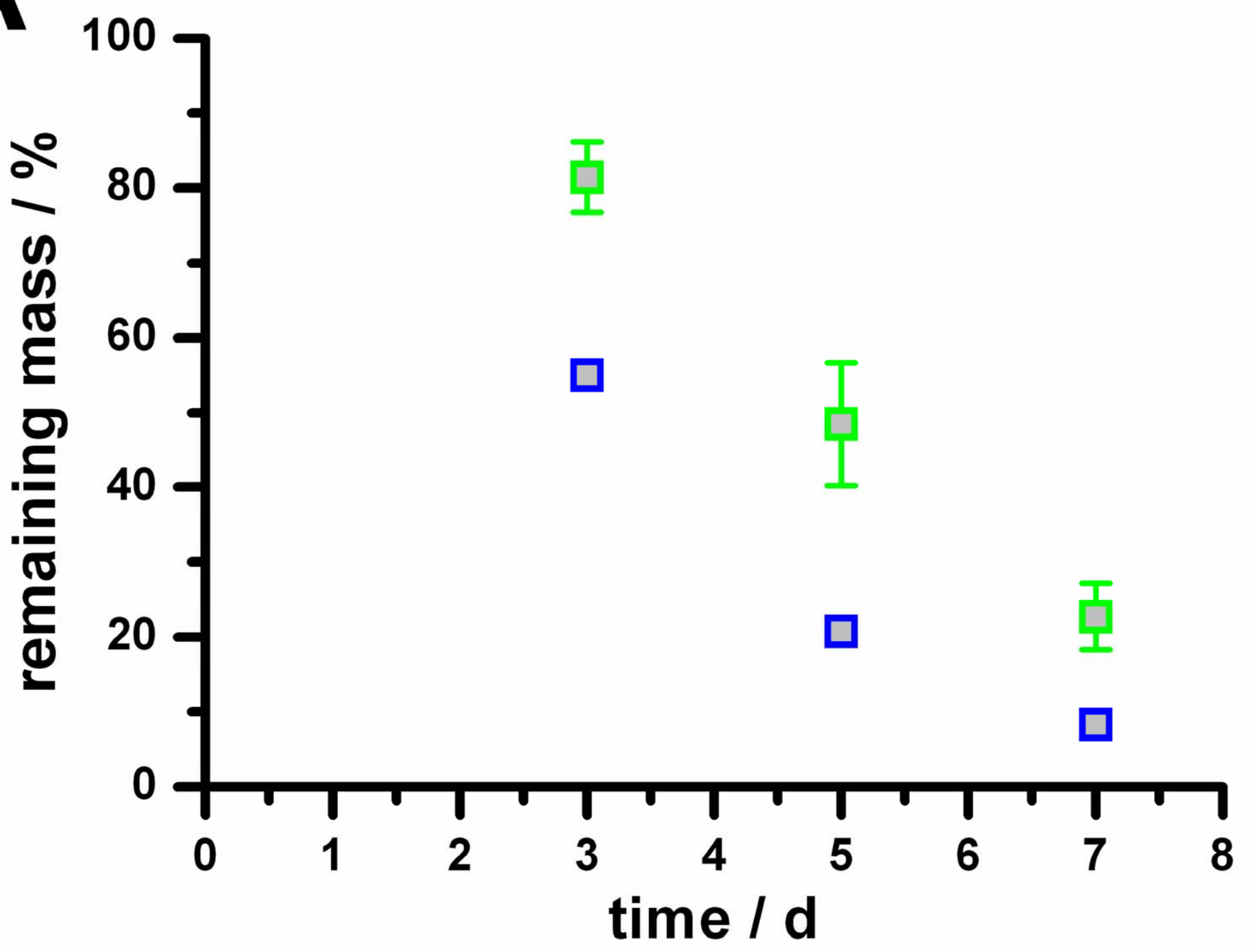




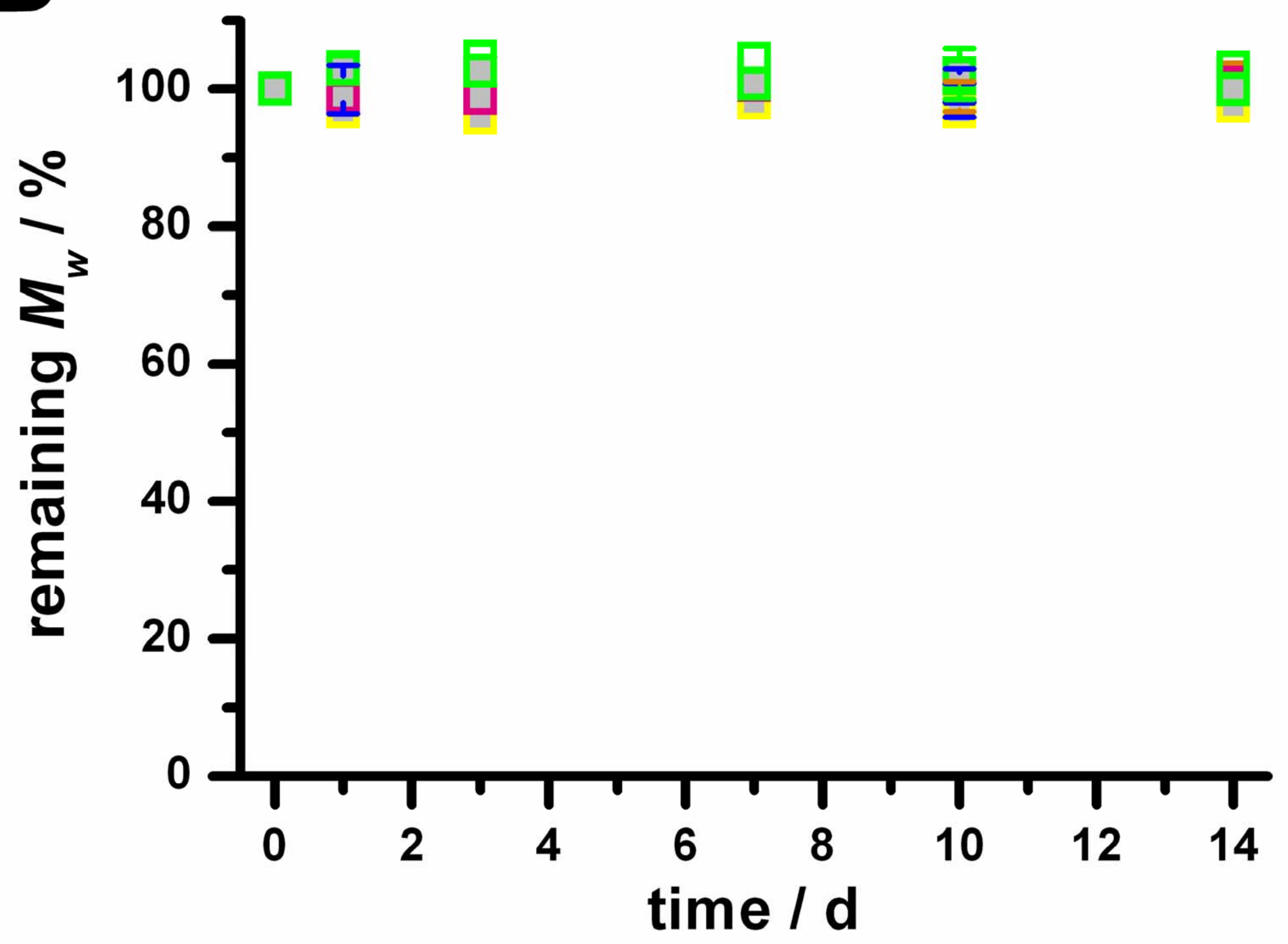




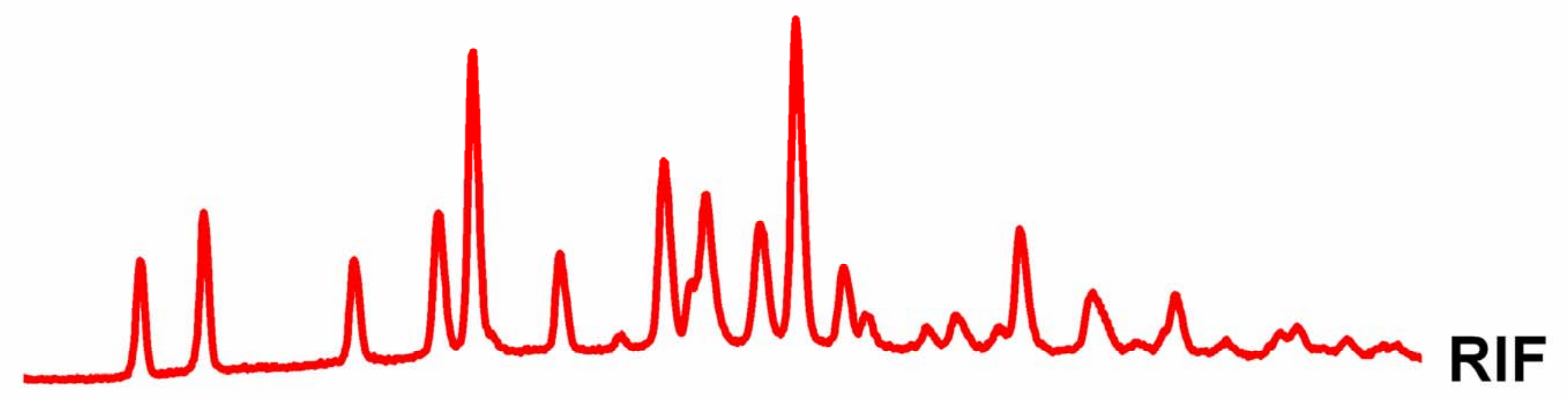

PEC85

PEC110

PEC133

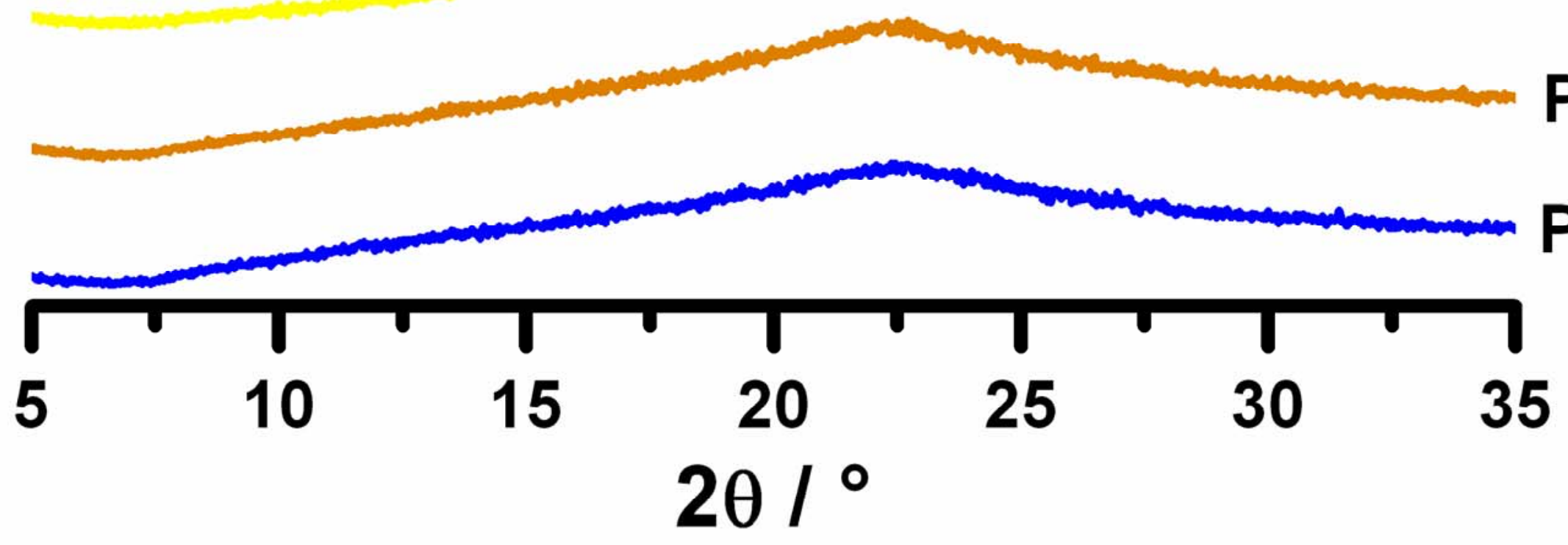

PEC174 PEC196 


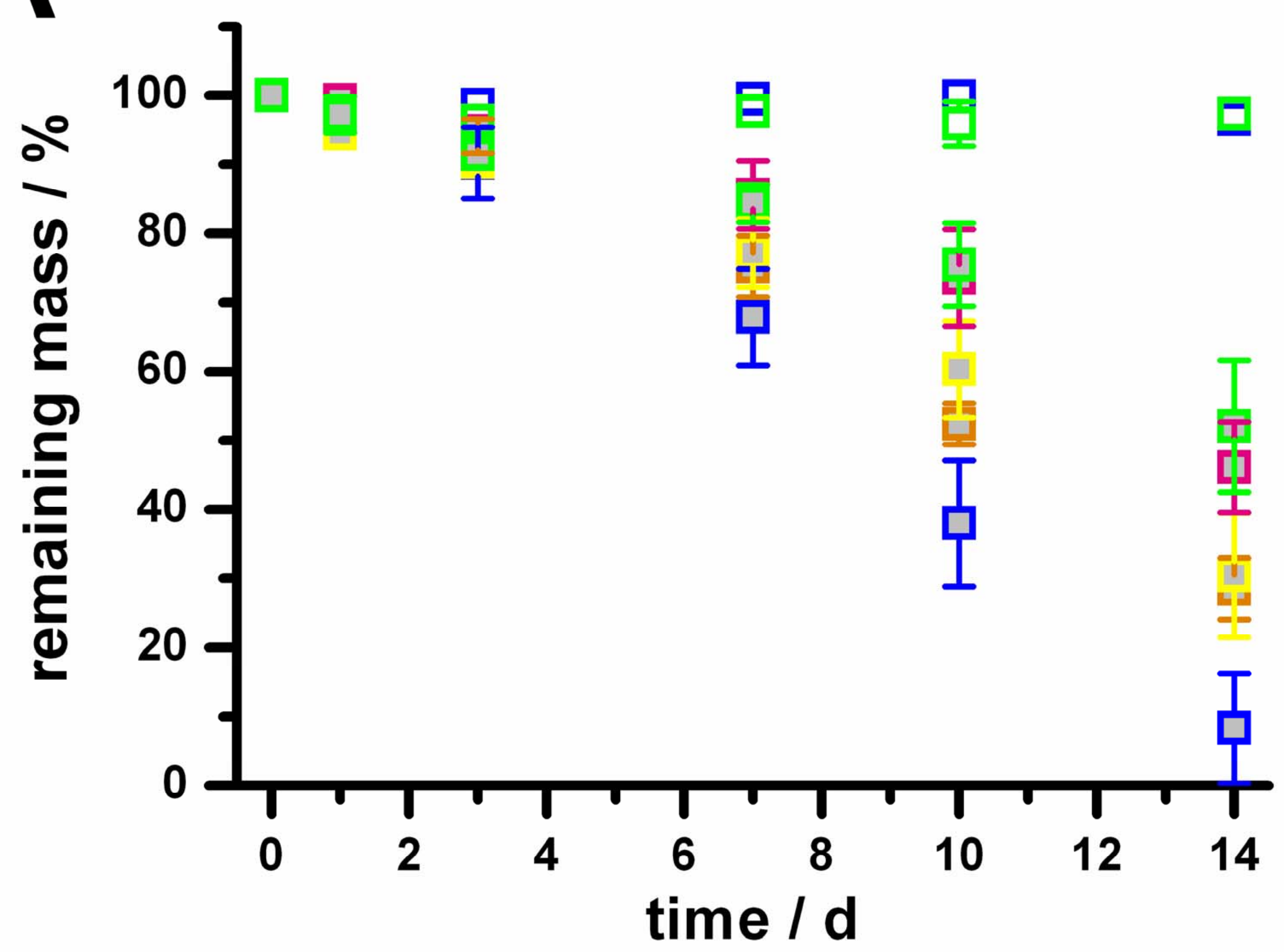




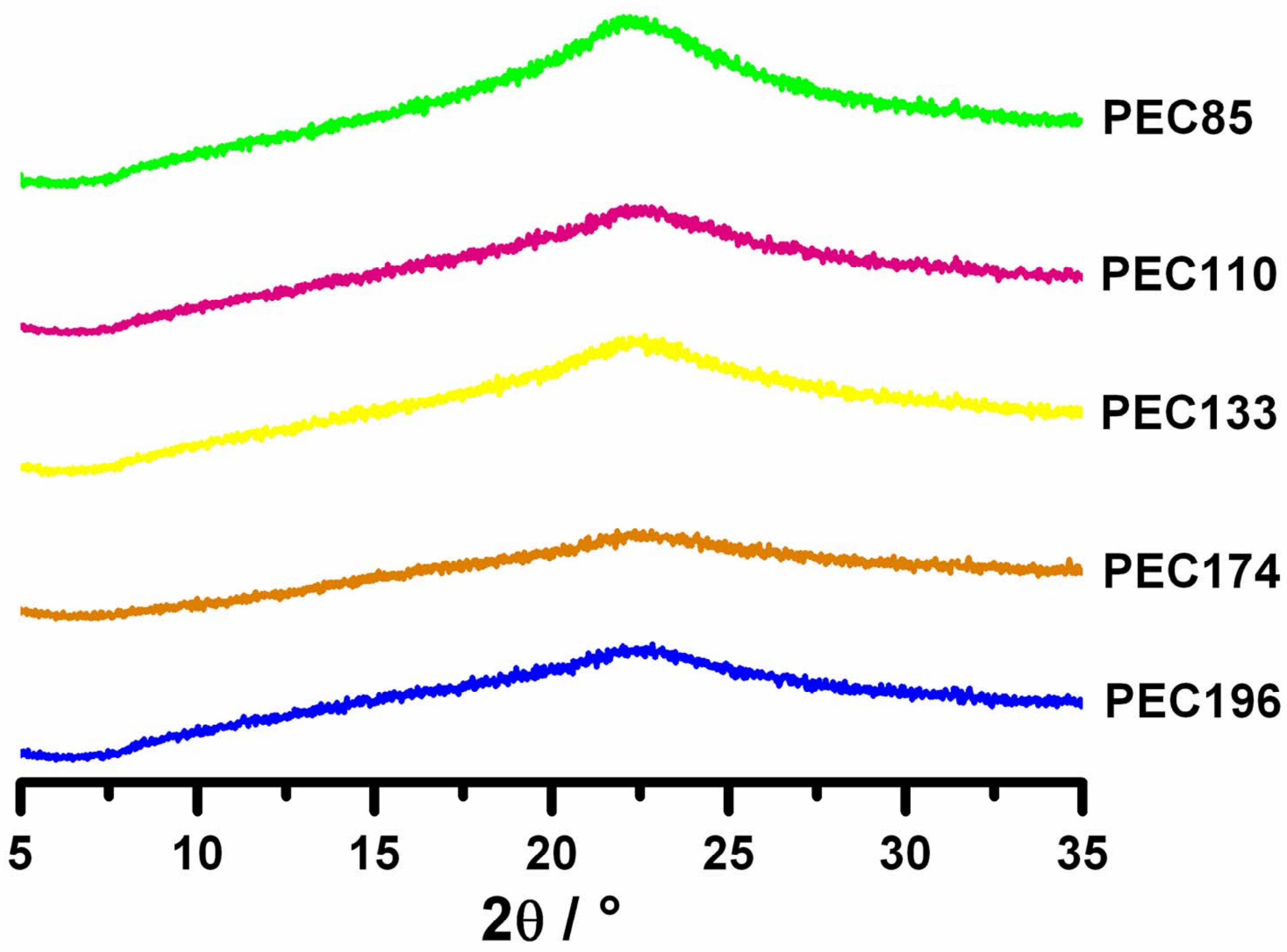




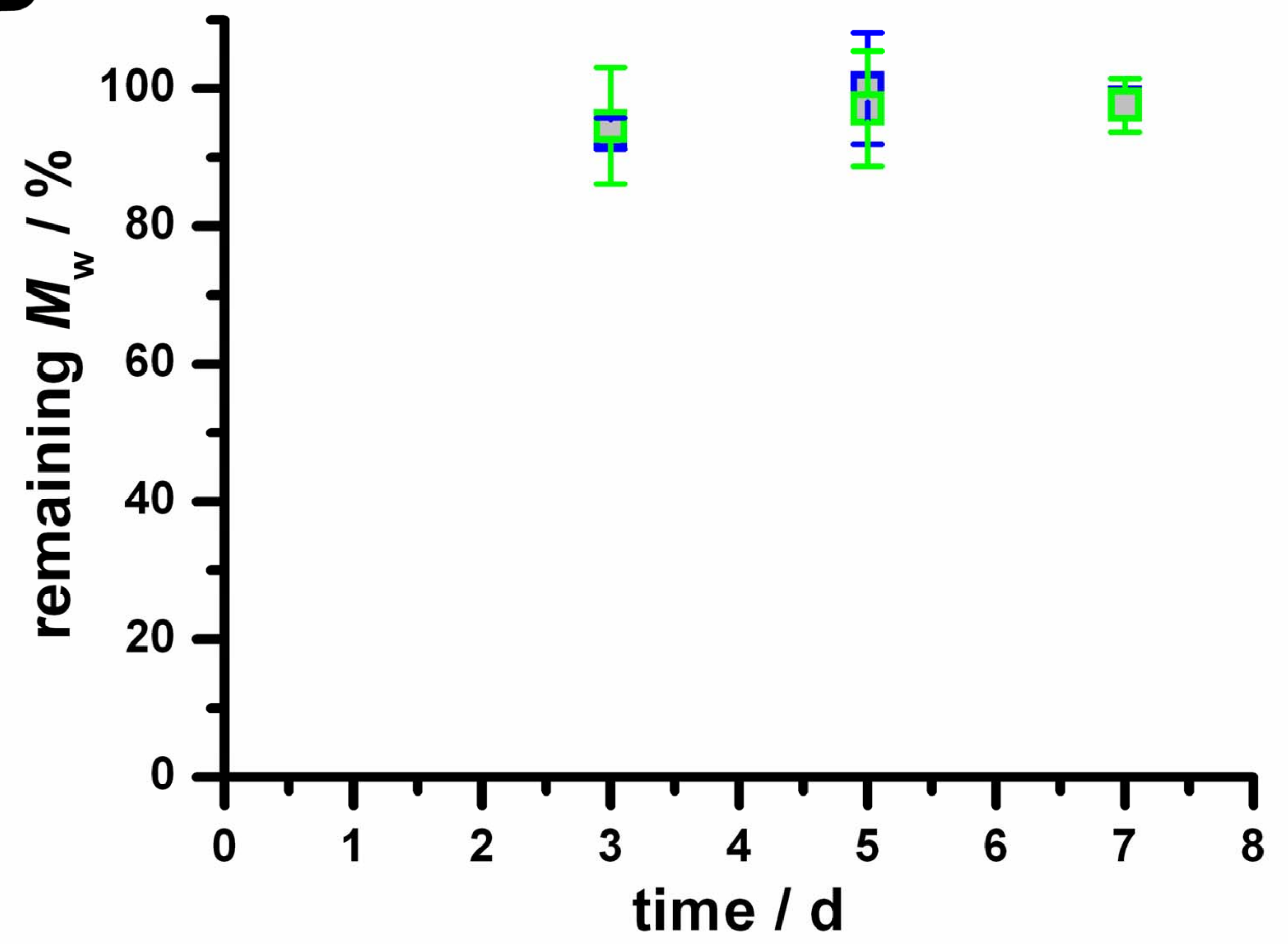

